\title{
Total Synthesis of Nortopsentin D via a Late-Stage Pinacol-like Rearrangement
}

Katarina L. Keel, and Jetze J. Tepe*

Michigan State University, Department of Chemistry, 578 S Shaw Ln, East Lansing, Ml 48824

Supporting Information Placeholder

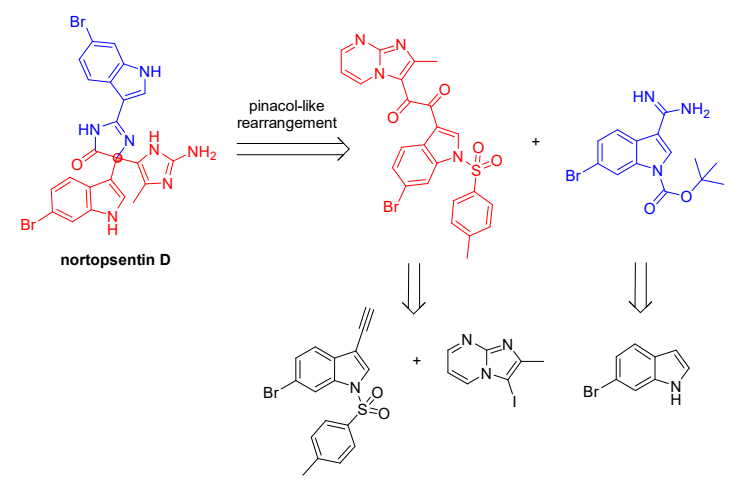

\footnotetext{
ABSTRACT: Nortopsentin D is part of a class of bis(indole) alkaloids known for their biological activity, including inhibitory activity in tumoral cells and antifungal activity. Herein we describe the first total synthesis of nortopsentin D, in which amidine and dione undergo a pivotal condensation and subsequent cyclization via a pinacol-like rearrangement. This synthesis represents a unique strategy for the formation of 5,5-disubstituted $(4 H)$-imidazol-4-one containing natural products, many of which have yet to succumb to total synthesis.
} 


\section{Table of Contents}

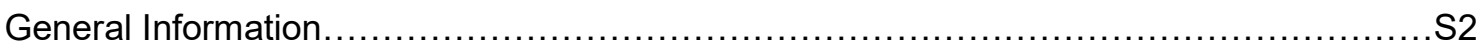

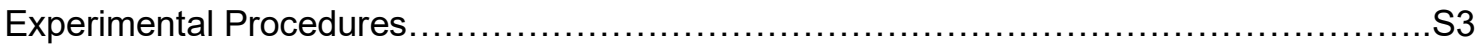

Table S1: Tabulated spectral comparison of nortopsentin D (1) to isolated natural

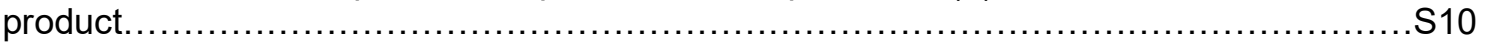

Crystallographic Analysis and Experimental...................................... 11

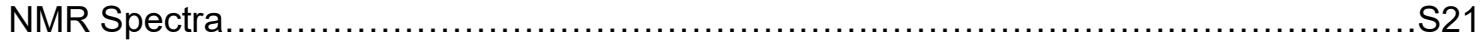

\section{General Information}

Reactions were carried out under a nitrogen atmosphere in flame-dried glassware. Solvents and reagents were purchased from commercial suppliers and used without further purification, unless otherwise mentioned. Anhydrous THF was distilled over sodium (dryness was monitored by the color of the solution, as indicated by benzophenone's ketyl radical), acetonitrile and triethylamine were distilled over calcium hydride, and toluene and dichloromethane were dried over molecular sieves directly before use. Magnetic stirring was used for all reactions. Yields refer to chromatographically and spectroscopically pure compounds unless otherwise noted. Infrared spectra were recorded on a Jasco Series 6600 FTIR spectrometer. ${ }^{1} \mathrm{H}$ and ${ }^{13} \mathrm{C}$ NMR spectra were recorded on a Varian Unity Plus-500 or 600 spectrometer. Chemical shifts are reported relative to the residue peaks of the solvent $\left(\mathrm{CDCl}_{3}: 7.26 \mathrm{ppm}\right.$ for ${ }^{1} \mathrm{H}$ and $77.0 \mathrm{ppm}$ for $\left.{ }^{13} \mathrm{C}\right)\left(\mathrm{DMSO}-\mathrm{d}_{6}: 2.50 \mathrm{ppm}\right.$ for ${ }^{1} \mathrm{H}$ and 39.5 ppm for ${ }^{13} \mathrm{C}$ ) (Acetone- $d_{6}: 2.05$ ppm for ${ }^{1} \mathrm{H}$ and $28.9 \mathrm{ppm}$ for $\left.{ }^{13} \mathrm{C}\right)\left(\mathrm{CD}_{3} \mathrm{OD}: 3.31 \mathrm{ppm}\right.$ for ${ }^{1} \mathrm{H}$ and $47.6 \mathrm{ppm}$ for $\left.{ }^{13} \mathrm{C}\right)$. The following abbreviations are used to denote the multiplicities: $s=$ singlet, $d=$ doublet, $d d=$ doublet of doublets, $t=$ triplet, and $m=$ multiplet. The following abbreviation is used to denote a broad signal: br = broad. HRMS were obtained at the Mass Spectrometry Facility of Michigan State University with a Micromass Q-ToF Ultima API LC-MS/MS mass spectrometer. Column chromatography was performed using a Teledyne ISCO CombiFlash® NextGen system with prepacked columns (RediSep® Normal-phase silica, 20-40 microns and RediSep® Rf Gold Reversed-Phase C18 silica, 20-40 microns). TLCs were performed on pre-coated $0.25 \mathrm{~mm}$ thick silica gel $60 \mathrm{~F} 254$ plates and pre-coated 150 um thick, C18 reverse phase F254 plates, visualized using UV light and iodine staining. 


\section{Experimental Procedures}

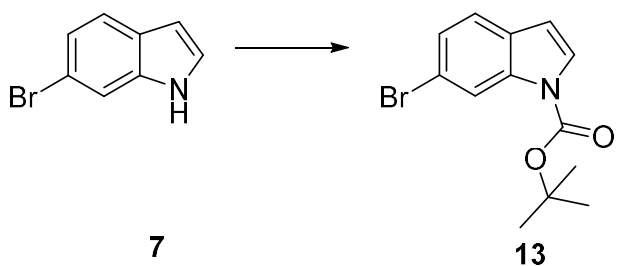

Tert-butyl 6-bromo-1H-indole-1-carboxylate (13): Commercially available 6-bromoindole (5 g, $25.5 \mathrm{mmol}$ ) was added to a clean, dry round bottom flask under nitrogen and dissolved in anhydrous dichloromethane $(50 \mathrm{~mL})$. To this solution, trimethylamine $(10.7 \mathrm{~mL}, 76.5 \mathrm{mmol})$ and 4-dimethylaminopyridine $(0.62 \mathrm{~g}, 5.1 \mathrm{mmol})$ were added. Di-tertbutyldicarbonate $(6.4 \mathrm{~mL}, 28 \mathrm{mmol})$ was then added dropwise to the solution. This reaction was stirred for 20 hours at room temperature. Once complete (as monitored via TLC), the reaction was quenched using water (40 $\mathrm{mL}$ ), and the crude organics were extracted into dichloromethane $(3 \times 50 \mathrm{~mL})$. The organics were dried over $\mathrm{Na}_{2} \mathrm{SO}_{4}$, concentrated in vacuo and purified using automated CombiFlash chromatography (silica gel, 20-40 microns, 100\% hexanes) to produce a white solid $(7.19 \mathrm{~g}, 96 \%$ yield).

${ }^{1} \mathrm{H}$ NMR $\left(500 \mathrm{MHz}, \mathrm{CDCl}_{3}\right) \delta 8.38(\mathrm{~s}, 1 \mathrm{H}), 7.57(\mathrm{~d}, J=3.7 \mathrm{~Hz}, 1 \mathrm{H}), 7.42(\mathrm{~d}, J=8.3 \mathrm{~Hz}, 1 \mathrm{H}), 7.35(\mathrm{dd}, J=8.3,1.8 \mathrm{~Hz}$, $1 \mathrm{H}), 6.54(\mathrm{dd}, J=3.7,0.7 \mathrm{~Hz}, 1 \mathrm{H}), 1.69(\mathrm{~s}, 9 \mathrm{H})$.

${ }^{13} \mathrm{C}$ NMR $\left(126 \mathrm{MHz}, \mathrm{CDCl}_{3}\right) \delta 149.4,135.9,129.3,126.3,125.9,122.0,118.4,117.9,107.0,84.2,28.1$.

IR (neat): $1731 \mathrm{~cm}^{-1}$. HRMS (ESI-TOF) m/z: Could not be identified. m.p.: $74{ }^{\circ} \mathrm{C}$

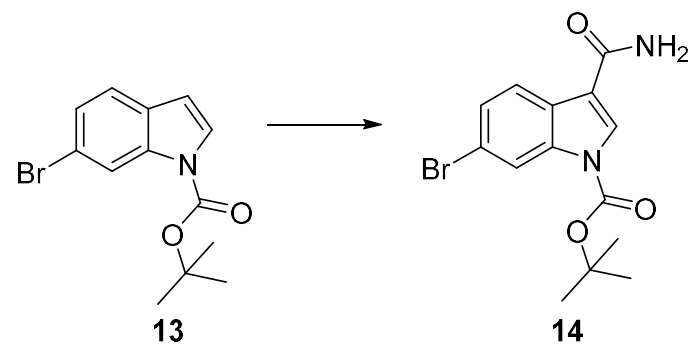

Tert-butyl 6-bromo-3-carbamoyl-1H-indole-1-carboxylate (14): 13 (0.98 g, $3.3 \mathrm{mmol})$ was added to a clean, dry round bottom flask under nitrogen and dissolved in $10 \mathrm{~mL}$ of anhydrous acetonitrile. The solution was cooled to $0^{\circ} \mathrm{C}$ using an ice bath. Chlorosulfonyl isocyanate $(0.29 \mathrm{~mL}, 3.3 \mathrm{mmol})$ was then added dropwise to the reaction over a period of 10 minutes. The reaction was stirred for 3 hours as it warmed to room temperature. Then, a solution of $9 \mathrm{~mL}$ of acetone and $1 \mathrm{~mL}$ of water was added to the reaction. The reaction was rendered alkaline upon addition of a $20 \%$ aqueous solution of $\mathrm{NaOH}$. The organics were then extracted into ethyl acetate $(3 \times 30 \mathrm{~mL})$. Organics were then combined and washed with brine, dried with $\mathrm{Na}_{2} \mathrm{SO}_{4}$ and concentrated in vacuo. The crude product was purified using automated CombiFlash chromatography (silica gel, 20-40 microns, ethyl acetate/hexanes gradient 0-100\%). The pure product was a white solid $(0.67 \mathrm{~g}, 58 \%$ yield).

${ }^{1} \mathrm{H}$ NMR $\left(500 \mathrm{MHz}, \mathrm{CDCl}_{3}\right) \delta 8.28(\mathrm{~s}, 1 \mathrm{H}), 8.07(\mathrm{~s}, 1 \mathrm{H}), 7.92(\mathrm{~d}, J=8.5 \mathrm{~Hz}, 1 \mathrm{H}), 7.37(\mathrm{dd}, J=8.5,1.8 \mathrm{~Hz}, 1 \mathrm{H}), 6.40(\mathrm{~s}$, br., $2 \mathrm{H}), 1.65$ (s, 9H).

${ }^{13} \mathrm{C} \mathrm{NMR}\left(126 \mathrm{MHz}, \mathrm{CDCl}_{3}\right) \delta 166.2,148.8,136.1,128.6,127.1,126.5,122.5,119.0,118.4,115.0,85.7,28.1$.

IR (neat): $3421,3349,1739,1648 \mathrm{~cm}^{-1}$. HRMS (ESI-TOF) m/z: $\left[(\mathrm{M}+\mathrm{H})^{+}\right]$calcd for $\left(\mathrm{C}_{14} \mathrm{H}_{16} \mathrm{BrN}_{2} \mathrm{O}_{3}{ }^{+}\right) 282.9718$ Found 282.9715. m.p.: $108^{\circ} \mathrm{C}$ 


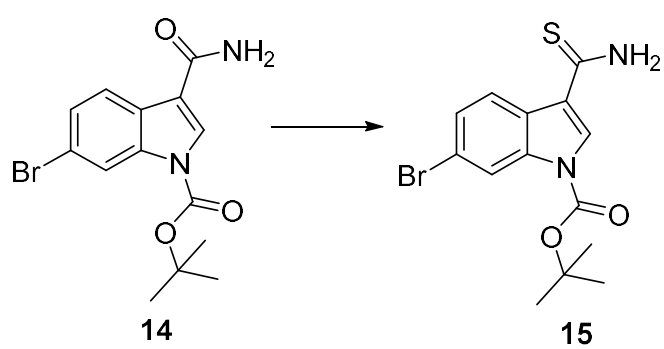

Tert-butyl 6-bromo-3-carbamothioyl-1H-indole-1-carboxylate (15): 14 (0.8 g, $2.36 \mathrm{mmol})$ was added to a clean, dry round bottom flask under nitrogen and dissolved in $60 \mathrm{~mL}$ of anhydrous toluene. Lawesson's reagent $(0.95 \mathrm{~g}, 2.36$ $\mathrm{mmol}$ ) was then added to the solution. The reaction was stirred and gently heated in an oil bath for 30 minutes, until the solution became homogenous and turned yellow in color. (Note: If this reaction is allowed to go too long, the solution will darken in color and undesired side products will form.) Once the reaction was complete, the solution was concentrated, and the crude reaction was purified using automated CombiFlash chromatography (silica gel, 20-40 microns, ethyl acetate/hexanes gradient $0-100 \%)$. Pure product is a yellow solid $(0.75 \mathrm{~g}, 89 \%$ yield).

${ }^{1} \mathrm{H}$ NMR $\left(500 \mathrm{MHz}\right.$, Acetone- $\left.d_{6}\right) \delta 8.78(\mathrm{~s}, \mathrm{br} ., 2 \mathrm{H}), 8.59(\mathrm{~d}, J=8.6 \mathrm{~Hz}, 1 \mathrm{H}), 8.38(\mathrm{~d}, J=1.9 \mathrm{~Hz}, 1 \mathrm{H}), 8.33(\mathrm{~s}, 1 \mathrm{H}), 7.50$ (dd, $J=8.6,1.9 \mathrm{~Hz}, 1 \mathrm{H}), 1.71(\mathrm{~s}, 9 \mathrm{H})$.

${ }^{13} \mathrm{C}$ NMR $\left(126 \mathrm{MHz}\right.$, Acetone- $\left.d_{6}\right) \delta$ 194.9, 149.6, 137.4, 128.1, 127.3, 127.2, 125.0, 121.5, 118.9, 118.7, 86.3, 28.1.

IR (neat): $3247,3119,2218 \mathrm{~cm}^{-1}$. HRMS (ESI-TOF) m/z: Could not be identified. m.p.: $179^{\circ} \mathrm{C}$

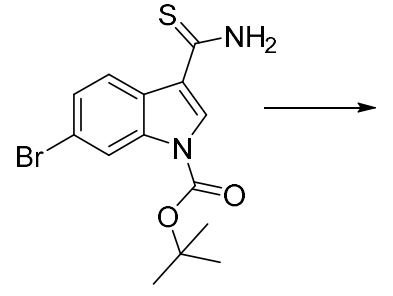

15<smiles>CSC(=N)c1cn(C(=O)OC(C)(C)C)c2cc(Br)ccc12</smiles>

16

Tert-butyl 6-bromo-3-(imino(methylthio)methyl)-1H-indole-1-carboxylate (16): 15 (0.5 g, $1.4 \mathrm{mmol}$ ) was added to a clean, dry round bottom flask under nitrogen and dissolved in $30 \mathrm{~mL}$ of acetone. Methyl iodide $(0.52 \mathrm{~mL}, 8.4 \mathrm{mmol})$ was added to the solution dropwise. The reaction was stirred at room temperature for 72 hours, or until the reaction was completed as monitored via TLC. Once complete, $30 \mathrm{~mL}$ of ethyl acetate was added to the reaction, and the reaction was washed with saturated sodium bicarbonate solution $(2 \times 30 \mathrm{~mL})$ and brine $(2 \times 30 \mathrm{~mL})$. Organics were then separated, dried with $\mathrm{Na}_{2} \mathrm{SO}_{4}$ and concentrated in vacuo. The crude product was purified using automated CombiFlash chromatography (silica gel, 20-40 microns, ethyl acetate/hexanes gradient 0-100\%). Pure product was a yellow solid (0.46 g, 89\%).

${ }^{1} \mathrm{H} \mathrm{NMR}\left(500 \mathrm{MHz}, \mathrm{CDCl}_{3}\right) \delta 9.42(\mathrm{~s}, \mathrm{br} ., 1 \mathrm{H}), 8.33(\mathrm{~s}, 1 \mathrm{H}), 8.22-8.04(\mathrm{~m}, 1 \mathrm{H}), 7.99(\mathrm{~s}, 1 \mathrm{H}), 7.39$ (dd, J = 8.5, $1.8 \mathrm{~Hz}$, $1 \mathrm{H}), 2.39(\mathrm{~s}, 3 \mathrm{H}), 1.67(\mathrm{~s}, 9 \mathrm{H})$.

${ }^{13} \mathrm{C}$ NMR (126 MHz, $\mathrm{CDCl}_{3}$ ) (Apodization set to exponential = $8 \mathrm{~Hz}$ for broad peak) $\delta 165.2(\mathrm{br}), 148.8,136.2,127.5$,

$126.9,126.2,123.2,119.6,118.9,118.3,85.2,28.1,12.0$.

IR (neat): 2972, $1741 \mathrm{~cm}^{-1}$. HRMS (ESI-TOF) m/z: $\left[(\mathrm{M}+\mathrm{H})^{+}\right]$calcd for $\left(\mathrm{C}_{15} \mathrm{H}_{18} \mathrm{BrN}_{2} \mathrm{O}_{2} \mathrm{~S}^{+}\right)$369.0272 Found 369.0263. m.p.: $141^{\circ} \mathrm{C}$<smiles>CSC(=N)c1cn(C(=O)OC(C)(C)C)c2cc(Br)ccc12</smiles>

16<smiles>CC(C)(C)OC(=O)n1cc(C(=N)N)c2ccc(Br)cc21</smiles>

4 
Tert-butyl 3-carbamimidoyl-1H-indole-1-carboxylate (4): 15 (0.38 g, $1 \mathrm{mmol}$ ) was added to a clean, dry round bottom flask under nitrogen and dissolved in $10 \mathrm{~mL}$ of methanol. Ammonium chloride $(0.1 \mathrm{~g}, 1.2 \mathrm{mmol})$ was added to the solution. The reaction was stirred and refluxed via heating mantle for 24 hours, monitoring progress via TLC. Once the reaction was complete it was cooled, and the solution was concentrated in vacuo. The crude product was purified using automated CombiFlash chromatography (silica gel, 20-40 microns, dichloromethane/methanol gradient 0-10\%). Pure product was a white solid $(0.26 \mathrm{~g}, 68 \%$ yield).

${ }^{1} \mathrm{H}$ NMR $\left(500 \mathrm{MHz}, \mathrm{CD}_{3} \mathrm{OD}\right) \delta 8.45(\mathrm{~s}, 1 \mathrm{H}), 8.45(\mathrm{~d}, J=1.8 \mathrm{~Hz}, 1 \mathrm{H}), 7.74(\mathrm{~d}, J=8.6 \mathrm{~Hz}, 1 \mathrm{H}), 7.56(\mathrm{dd}, J=8.6,1.8 \mathrm{~Hz}$, $1 \mathrm{H}), 1.72(\mathrm{~s}, 9 \mathrm{H})$.

${ }^{13} \mathrm{C}$ NMR $\left(126 \mathrm{MHz}, \mathrm{CD}_{3} \mathrm{OD}\right) \delta 162.4,149.4,137.5,132.6,128.5,125.9,122.5,120.6,119.7,110.5,87.8,28.1$.

IR (neat): $3302,3119,1649,1569 \mathrm{~cm}^{-1}$. HRMS (ESI-TOF) m/z: $\left[(\mathrm{M}+\mathrm{H})^{+}\right]$calcd for $\left(\mathrm{C}_{14} \mathrm{H}_{17} \mathrm{BrN}_{3} \mathrm{O}_{2}{ }^{+}\right) 338.0499$ Found: 338.0511. m.p.: salt, $>200^{\circ} \mathrm{C}$.

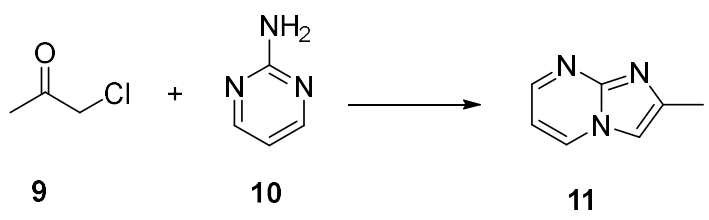

3-methylimidazo[1,2-a]pyrimidine (11): Commercially available 2-aminopyrimidine (4 g, $42 \mathrm{mmol})$ was added to a clean, dry round bottom flask under nitrogen and dissolved in $50 \mathrm{~mL}$ of ethanol. The solution was stirred at room temperature, and commercially available chloroacetone $(3.7 \mathrm{~mL}, 46 \mathrm{mmol})$ was added to the reaction dropwise. After an hour of stirring at room temperature, the reaction was stirred and refluxed via heating mantle for 20 hours. Once complete, the reaction was cooled to room temperature and concentrated in vacuo. To workup, the crude product was dissolved in $30 \mathrm{~mL}$ of water, and the $\mathrm{pH}$ was adjusted to 8-9 using a saturated aqueous solution of $\mathrm{Na}_{2} \mathrm{CO}_{3}$. The organics were extracted into dichloromethane $(3 \times 50 \mathrm{~mL})$. The organics were then dried with $\mathrm{Na}_{2} \mathrm{SO}_{4}$ and concentrated in vacuo. The crude product was purified using automated CombiFlash chromatography (silica gel, 20-40 microns, ethyl acetate/hexanes gradient $0-100 \%$, then dichloromethane with $5 \%$ methanol). The product was an off-white solid ( $3.27 \mathrm{~g}$, $58 \%$ yield).

${ }^{1} \mathrm{H} \mathrm{NMR}\left(500 \mathrm{MHz}, \mathrm{CDCl}_{3}\right) \delta 8.42(\mathrm{dd}, J=4.1,2.0 \mathrm{~Hz}, 1 \mathrm{H}), 8.36(\mathrm{dd}, J=6.7,2.0 \mathrm{~Hz}, 1 \mathrm{H}), 7.29(\mathrm{~s}, 1 \mathrm{H}), 6.77$ (dd, $J=6.7$, $4.1 \mathrm{~Hz}, 1 \mathrm{H}), 2.46(\mathrm{~s}, 3 \mathrm{H})$.

${ }^{13} \mathrm{C}$ NMR $\left(126 \mathrm{MHz}, \mathrm{CDCl}_{3}\right) \delta 158.3,149.0,145.7,132.6,108.2,107.8,14.9$.

IR (neat): 3104, 3059, 2939, 2601, 2531, 2488, $2364 \mathrm{~cm}^{-1}$. HRMS (ESI-TOF) m/z: [(M+H) $\left.{ }^{+}\right]$calcd for $\left(\mathrm{C}_{7} \mathrm{H}_{8} \mathrm{~N}_{3}{ }^{+}\right)$

134.0713 Found: 134.0722 . m.p.: decomposed at $143^{\circ} \mathrm{C}$.

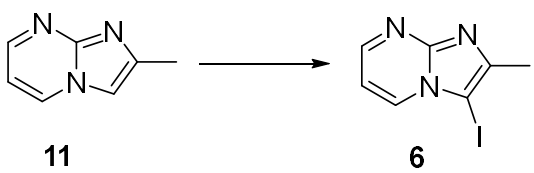

2-iodo-3-methylimidazo[1,2-a]pyrimidine (6): 11 (1.0 g, $7.5 \mathrm{mmol}$ ) was added to a clean, dry round bottom flask under nitrogen and dissolved in $10 \mathrm{~mL}$ of anhydrous dimethylformamide. The solution was cooled to $0^{\circ} \mathrm{C}$ in an ice bath. $\mathrm{N}$ iodosuccinimide $(2.0 \mathrm{~g}, 9.0 \mathrm{mmol})$ was added to the reaction portion wise. The reaction was stirred and allowed to warm to room temperature overnight. Once complete, a saturated aqueous solution of sodium bicarbonate $(20 \mathrm{~mL})$ was added to the reaction, and the solution was stirred for 1 hour. The reaction was then diluted in $40 \mathrm{~mL}$ of dichloromethane and washed with a saturated aqueous solution of sodium bicarbonate $(20 \mathrm{~mL})$, an aqueous solution of sodium thiosulfate (30 $\mathrm{mL}$ ), and a brine solution $(30 \mathrm{~mL})$. The organics were dried over $\mathrm{Na}_{2} \mathrm{SO}_{4}$ and concentrated in vacuo to provide a pure white solid ( $1.67 \mathrm{~g}, 86 \%$ yield).

${ }^{1} \mathrm{H}$ NMR $\left(500 \mathrm{MHz}\right.$, Acetone- $\left.d_{6}\right) \delta 8.59$ (dd, $\left.J=6.8,1.9 \mathrm{~Hz}, 1 \mathrm{H}\right), 8.47$ (dd, $\left.J=4.1,1.9 \mathrm{~Hz}, 1 \mathrm{H}\right), 7.13(\mathrm{dd}, J=6.7,4.1 \mathrm{~Hz}$, $1 \mathrm{H}), 2.44(\mathrm{~s}, 3 \mathrm{H})$.

${ }^{13} \mathrm{C}$ NMR $\left(126 \mathrm{MHz}\right.$, Acetone- $\left.d_{6}\right) \delta 151.7,150.5,150.0,134.8,110.2,61.6,15.4$. 
IR (neat): $3087,3053,2988 \mathrm{~cm}^{-1}$. HRMS (ESI-TOF) m/z: $\left[(\mathrm{M}+\mathrm{H})^{+}\right]$calcd for $\left(\mathrm{C}_{7} \mathrm{H}_{7} \mathrm{IN}_{3}{ }^{+}\right)$259.9679 Found: 259.9700. m.p.: $118^{\circ} \mathrm{C}$.

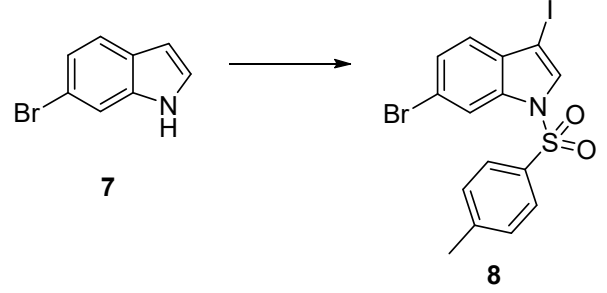

6-bromo-3-iodo-1-tosyl-1H-indole (8): Commercially available 6-bromoindole (2.0 g, $10.2 \mathrm{mmol}$ ) was added to a clean, dry round bottom flask under nitrogen and dissolved in $20 \mathrm{~mL}$ of dimethylformamide. Potassium hydroxide (1.4 g, 25.5 $\mathrm{mmol}$ ) was added to the reaction, and it was stirred for 5 minutes. Then, $\mathrm{I}_{2}(2.6 \mathrm{~g}, 10.2 \mathrm{mmol})$ was added to the reaction. The reaction was stirred for 1 hour at room temperature. Once complete, the reaction was quenched with a saturated aqueous $\mathrm{Na}_{2} \mathrm{~S}_{2} \mathrm{O}_{3}$ solution $(20 \mathrm{~mL})$ and extracted into ethyl acetate $(40 \mathrm{~mL})$. The organics were dried with $\mathrm{Na}_{2} \mathrm{SO}_{4}$ and concentrated in vacuo. The crude product was then dissolved in anhydrous $\mathrm{THF}$, and the solution was cooled to $0^{\circ} \mathrm{C}$. Triethylamine (2.8 mL, $20.4 \mathrm{mmol})$ and 4-dimethylaminopyridine $(0.25 \mathrm{~g}, 2.4 \mathrm{mmol})$ were added to the solution, and it was stirred for 10 minutes. Then, a freshly recrystallized batch of 4-toluenesulfonyl chloride $(2.3 \mathrm{~g}, 12.2 \mathrm{mmol})$ was added to the reaction slowly, and it was stirred at room temperature overnight. Once complete as monitored by TLC, dichloromethane $(50 \mathrm{~mL})$ was added to the reaction, and the organics were washed with brine solution $(50 \mathrm{~mL})$. The organics were then dried with $\mathrm{Na}_{2} \mathrm{SO}_{4}$ and concentrated in vacuo. The crude product was purified using automated CombiFlash chromatography (silica gel, 20-40 microns, ethyl acetate/hexanes gradient 0-100\%). The pure product was a white solid (4.4 g, 91\% yield).

${ }^{1} \mathrm{H}$ NMR $\left(500 \mathrm{MHz}, \mathrm{CDCl}_{3}\right) \delta 8.16(\mathrm{~d}, J=1.7 \mathrm{~Hz}, 1 \mathrm{H}), 7.79(\mathrm{~d}, J=8.5 \mathrm{~Hz}, 2 \mathrm{H}), 7.66(\mathrm{~s}, 1 \mathrm{H}), 7.42(\mathrm{dd}, J=8.4,1.7 \mathrm{~Hz}$, $1 \mathrm{H}), 7.27(\mathrm{~d}, J=8.1 \mathrm{~Hz}, 2 \mathrm{H}), 7.22(\mathrm{~d}, J=8.4 \mathrm{~Hz}, 1 \mathrm{H}), 2.37(\mathrm{~s}, 3 \mathrm{H})$.

${ }^{13} \mathrm{C}$ NMR $\left(126 \mathrm{MHz}, \mathrm{CDCl}_{3}\right) \delta 145.9,134.9,134.7,131.5,130.3,130.3,127.4,127.0,123.3,119.7,116.5,66.4,21.8$. IR (neat): 2980, 2950, 2605, $2499 \mathrm{~cm}^{-1}$. HRMS (ESI-TOF) m/z: Could not be identified. m.p.: $133^{\circ} \mathrm{C}$.

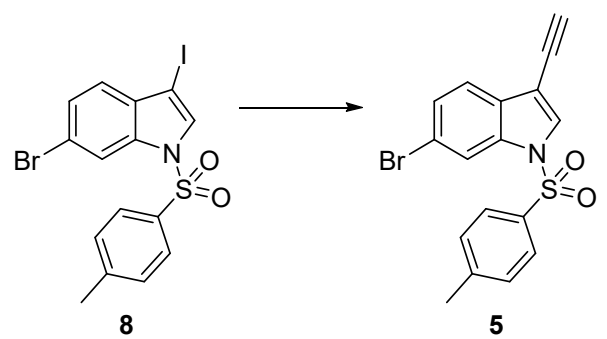

6-bromo-3-ethynyl-1-tosyl-1H-indole (5): $8(0.5 \mathrm{~g}, 1.05 \mathrm{mmol})$ was added to a clean, dry three-neck flask under argon and dissolved in $6 \mathrm{~mL}$ of anhydrous dimethylformamide and $6 \mathrm{~mL}$ of anhydrous triethylamine. The solution was sparged with argon for 30 minutes. Once complete, $\mathrm{Pd}\left(\mathrm{PPh}_{3}\right)_{2} \mathrm{Cl}_{2}(7.4 \mathrm{mg}, 0.01 \mathrm{mmol})$ and $\mathrm{Cul}(4 \mathrm{mg}, 0.02 \mathrm{mmol})$ were added to the reaction. The reaction was then sealed and put under argon via argon balloon. Trimethylsilylethyne $(0.15 \mathrm{~mL}, 1.05$ $\mathrm{mmol}$ ) was added to the reaction dropwise as it stirred at room temperature for 3 hours. Once complete, as monitored by TLC, the reaction was quenched with water $(15 \mathrm{~mL})$. Organics were extracted into dichloromethane $(3 \times 30 \mathrm{~mL})$, dried with $\mathrm{Na}_{2} \mathrm{SO}_{4}$ and concentrated in vacuo. The crude product was then dissolved in 30-40 $\mathrm{mL}$ of dichloromethane and cooled to $0^{\circ} \mathrm{C}$. Tetrabutylammonium fluoride $(1.16 \mathrm{~mL}, 1 \mathrm{M}$ in THF) was added to the reaction dropwise as it stirred for 10 minutes. When complete, as monitored by TLC, the crude reaction was concentrated in vacuo and purified using automated CombiFlash chromatography (silica gel, 20-40 microns, ethyl acetate/hexanes gradient 0-100\%). The pure product was a white solid $(0.3 \mathrm{~g}, 76 \%)$.

${ }^{1} \mathrm{H} \mathrm{NMR}\left(500 \mathrm{MHz}, \mathrm{CDCl}_{3}\right) \delta 8.16(\mathrm{~d}, J=1.7 \mathrm{~Hz}, 1 \mathrm{H}), 7.78(\mathrm{~d}, J=8.4 \mathrm{~Hz}, 2 \mathrm{H}), 7.75(\mathrm{~s}, 1 \mathrm{H}), 7.48(\mathrm{~d}, J=8.4 \mathrm{~Hz}, 1 \mathrm{H})$, $7.40(\mathrm{dd}, J=8.4,1.7 \mathrm{~Hz}, 1 \mathrm{H}), 7.26(\mathrm{~d}, J=8.1 \mathrm{~Hz}, 2 \mathrm{H}), 3.27(\mathrm{~s}, 1 \mathrm{H}), 2.35(\mathrm{~s}, 3 \mathrm{H})$. 
${ }^{13} \mathrm{C}$ NMR $\left(126 \mathrm{MHz}, \mathrm{CDCl}_{3}\right) \delta 145.9,134.7,134.6,130.3,130.3,129.7,127.4,127.1,121.8,119.4,116.7,104.1,82.1$,

74.4, 21.7.

IR (neat): $3297,2113 \mathrm{~cm}^{-1}$. HRMS (ESI-TOF) m/z: [(M+H) $\left.)^{+}\right]$calcd for $\left(\mathrm{C}_{17} \mathrm{H}_{13} \mathrm{BrNO}_{2} \mathrm{~S}^{+}\right) 373.9845,375.9831$ Found:

373.9849, 375.9831. m.p.: $99^{\circ} \mathrm{C}$.
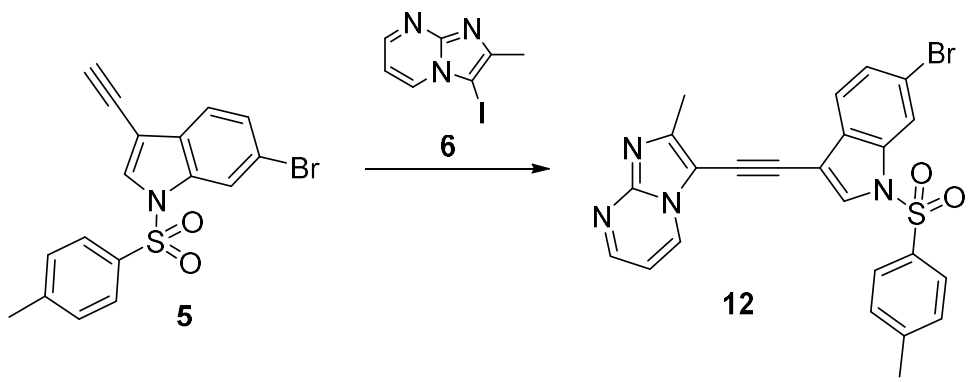

2-((6-bromo-1-tosyl-1H-indol-3-yl)ethynyl)-3-methylimidazo[1,2-a]pyrimidine (12): 5 (1 g, $2.7 \mathrm{mmol})$ and 6 (0.9 g, $3.5 \mathrm{mmol}$ ) were added to a clean, dry round bottom 3-neck flask under argon and dissolved in $15 \mathrm{~mL}$ of dimethylformamide. Diisopropylethylamine $(0.7 \mathrm{~mL}, 4.0 \mathrm{mmol})$ was added to the reaction, and the solution was sparged with argon for 30 minutes. After sparging with argon, $\mathrm{Pd}\left(\mathrm{PPh}_{3}\right)_{2} \mathrm{Cl}_{2}(94 \mathrm{mg}, 0.13 \mathrm{mmol})$ and $\mathrm{Cul}(51 \mathrm{mg}, 0.27 \mathrm{mmol})$ were added to the reaction, and it was sealed and put under argon via argon balloon. The reaction was stirred at room temperature for 16 hours. Once the reaction was complete, it was quenched with $30 \mathrm{~mL}$ of water, and the organics were extracted into dichloromethane $(3 \times 30 \mathrm{~mL})$. The organics were dried with $\mathrm{Na}_{2} \mathrm{SO}_{4}$ and concentrated in vacuo. The crude product was purified using automated CombiFlash chromatography (silica gel, 20-40 microns, ethyl acetate/hexanes gradient $0-100 \%)$. The pure product was a yellow solid. (1.15 g, $85 \%$ yield).

${ }^{1} \mathrm{H}$ NMR $\left(500 \mathrm{MHz}, \mathrm{CDCl}_{3}\right) \delta 8.56(\mathrm{dd}, J=4.2,2.0 \mathrm{~Hz}, 1 \mathrm{H}), 8.53(\mathrm{dd}, J=6.7,2.1 \mathrm{~Hz}, 1 \mathrm{H}), 8.18(\mathrm{~d}, J=1.6 \mathrm{~Hz}, 1 \mathrm{H}), 7.85$ $-7.79(\mathrm{~m}, 3 \mathrm{H}), 7.52(\mathrm{~d}, J=8.3 \mathrm{~Hz}, 1 \mathrm{H}), 7.44(\mathrm{dd}, J=8.3,1.7 \mathrm{~Hz}, 1 \mathrm{H}), 7.30(\mathrm{~d}, J=8.0 \mathrm{~Hz}, 2 \mathrm{H}), 6.98(\mathrm{dd}, J=6.7,4.1 \mathrm{~Hz}$, $1 \mathrm{H}), 2.64(\mathrm{~s}, 3 \mathrm{H}), 2.38(\mathrm{~s}, 3 \mathrm{H})$.

${ }^{13} \mathrm{C} \mathrm{NMR}\left(126 \mathrm{MHz}, \mathrm{CDCl}_{3}\right) \delta 151.3,150.5,148.0,146.1,134.9,134.6,132.4,130.4,129.5,129.3,127.5,127.1,121.6$, $119.6,116.9,109.3,104.8,104.3,91.3,80.0,21.8,15.0$.

IR (neat): 2982, 2625, 2609, 2502, $2361 \mathrm{~cm}^{-1}$. HRMS (ESI-TOF) m/z: [(M+H)+] calcd for $\left(\mathrm{C}_{24} \mathrm{H}_{18} \mathrm{BrN}_{4} \mathrm{O}_{2} \mathrm{~S}^{+}\right)$505.0328, 507.0316 Found: 505.0337, 507.0320. m.p.: $204^{\circ} \mathrm{C}$.
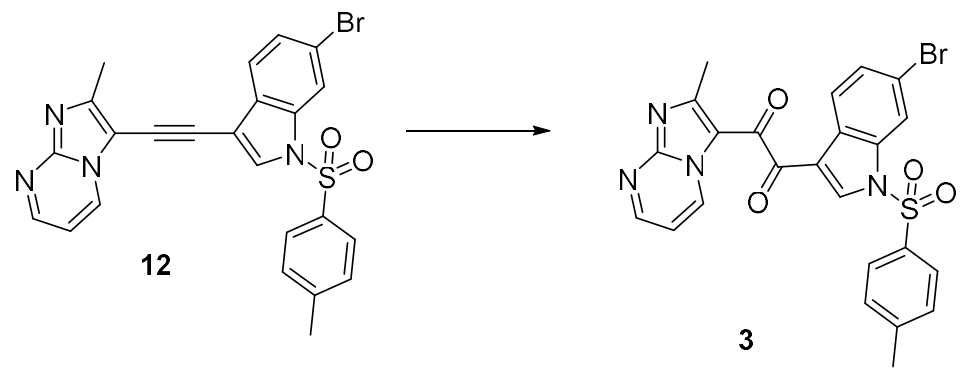

1-(6-bromo-1-tosyl-1H-indol-3-yl)-2-(3-methylimidazo[1,2-a]pyrimidin-2-yl)ethane-1,2-dione (3): 12 (0.1 g, 0.2 $\mathrm{mmol}$ ) was added to a clean, dry round bottom flask under air and dissolved in $3 \mathrm{~mL}$ of anhydrous DMF. Mercuric nitrate monohydrate $(0.14 \mathrm{~g}, 0.4 \mathrm{mmol})$ was added to the reaction, and it was stirred at room temperature for 18 hours. Once complete as determined by TLC, $10 \mathrm{~mL}$ of water was added to the reaction. Organics were extracted into ethyl acetate $(3 \times 40 \mathrm{~mL})$. The organics were combined and washed with water $(50 \mathrm{~mL})$ and a saturated brine solution $(50 \mathrm{~mL})$. The organics were dried with $\mathrm{Na}_{2} \mathrm{SO}_{4}$ and concentrated in vacuo. The crude product was purified using automated CombiFlash chromatography (silica gel, 20-40 microns, ethyl acetate/hexanes gradient 0-100\%). The pure product was a yellow solid (52 $\mathrm{mg}, 49 \%$ yield).

${ }^{1} \mathrm{H}$ NMR $\left(500 \mathrm{MHz}, \mathrm{CDCl}_{3}\right) \delta 9.70$ (dd, $\left.J=6.7,2.0 \mathrm{~Hz}, 1 \mathrm{H}\right), 8.58(\mathrm{dd}, J=4.3,2.1 \mathrm{~Hz}, 1 \mathrm{H}), 8.05(\mathrm{~s}, 1 \mathrm{H}), 8.01(\mathrm{~d}, J=8.5$ $\mathrm{Hz}, 1 \mathrm{H}), 7.89(\mathrm{~s}, 1 \mathrm{H}), 7.59(\mathrm{~d}, J=8.0 \mathrm{~Hz}, 2 \mathrm{H}), 7.32-7.26(\mathrm{~m}, 1 \mathrm{H}), 7.08(\mathrm{~d}, J=8.0 \mathrm{~Hz}, 2 \mathrm{H}), 7.00(\mathrm{dt}, J=6.8,3.8 \mathrm{~Hz}$, $1 \mathrm{H}), 2.24(\mathrm{~s}, 3 \mathrm{H}), 2.15(\mathrm{~s}, 3 \mathrm{H})$. 
${ }^{13} \mathrm{C} \mathrm{NMR}\left(126 \mathrm{MHz} \mathrm{CDCl}_{3}\right) \delta 187.4,182.2,159.1,154.6,151.2,146.9,136.9,136.1,135.6,133.8,130.7,129.0,127.5$, 126.2, 124.1, 120.4, 117.5, 116.6, 116.5, 111.7, 21.9, 17.5 .

IR (neat): 2915, 2849, 1653, $1598 \mathrm{~cm}^{-1}$. HRMS (ESI-TOF) m/z: [(M+H)+] calcd for $\left(\mathrm{C}_{24} \mathrm{H}_{18} \mathrm{BrN}_{4} \mathrm{O}_{4} \mathrm{~S}^{+}\right) 537.0232,539.0214$ Found: $537.0243,539.0214$. m.p.: $141^{\circ} \mathrm{C}$.
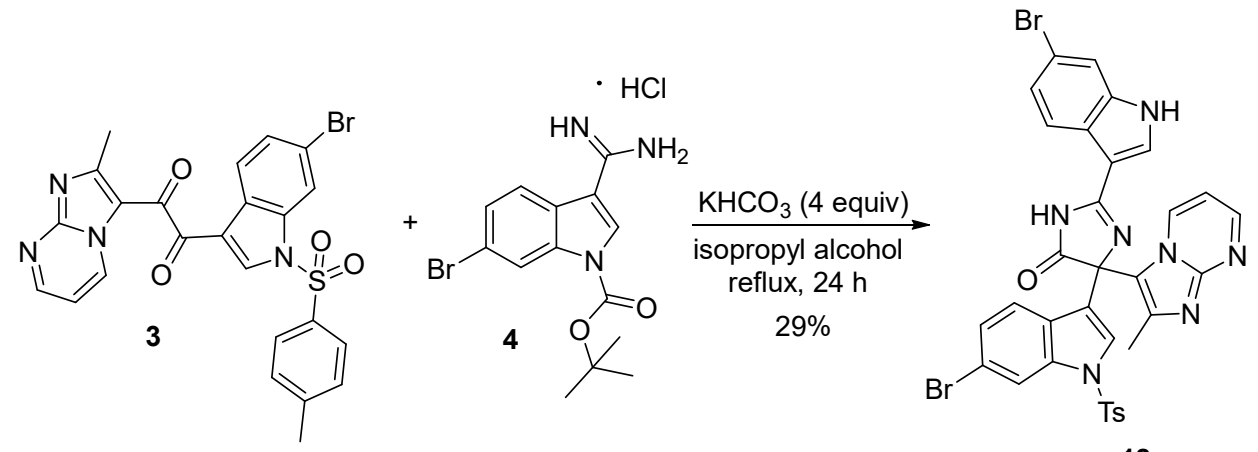

18

5-(6-bromo-1-tosyl-1H-indol-3-yl)-2-(6-bromo-1H-indol-3-yl)-5-(3-methylimidazo[1,2-a]pyrimidin-2-yl)-3,5-dihydro4H-imidazol-4-one (18): 4 (25 mg, $0.067 \mathrm{mmol}$ ) was added to a clean, dry round bottom flask under nitrogen and dissolved in $5 \mathrm{~mL}$ of isopropyl alcohol. Potassium bicarbonate (22 $\mathrm{mg}, 0.22 \mathrm{mmol}$ ) was added to the reaction, and it stirred at room temperature for 10 minutes. $3(30 \mathrm{mg}, 0.056 \mathrm{mmol})$ was then added to the reaction, and the reaction stirred and refluxed via heating mantle overnight. Once the cyclization was complete as monitored by TLC, the reaction was concentrated in vacuo, and the crude product was purified using automated CombiFlash chromatography (silica gel, 20-40 microns, dichloromethane/methanol gradient 0-10\%). The pure product was an off-white solid (12 mg, 29\% yield). ${ }^{1} \mathrm{H}$ NMR $\left(500 \mathrm{MHz}\right.$, Acetone- $\left.d_{6}\right) \delta 11.52$ (s, br.,1H), 11.29 (s, br., $\left.1 \mathrm{H}\right), 8.93$ (dd, $\left.J=7.0,2.0 \mathrm{~Hz}, 1 \mathrm{H}\right), 8.44-8.38(\mathrm{~m}, 3 \mathrm{H})$, $8.14(\mathrm{~d}, J=1.8 \mathrm{~Hz}, 1 \mathrm{H}), 7.94(\mathrm{~d}, J=8.1 \mathrm{~Hz}, 2 \mathrm{H}), 7.87(\mathrm{~s}, 1 \mathrm{H}), 7.80(\mathrm{~d}, J=1.8 \mathrm{~Hz}, 1 \mathrm{H}), 7.50(\mathrm{~d}, J=8.6 \mathrm{~Hz}, 1 \mathrm{H}), 7.42(\mathrm{~d}$, $J=8.0 \mathrm{~Hz}, 2 \mathrm{H}$ ), 7.32 (ddd, $J=8.2,6.0,1.7 \mathrm{~Hz}, 2 \mathrm{H}), 6.81$ (dd, $J=7.0,4.1 \mathrm{~Hz}, 1 \mathrm{H}), 2.61(\mathrm{~s}, 3 \mathrm{H}), 2.35(\mathrm{~s}, 3 \mathrm{H}$ ).

${ }^{13} \mathrm{C}$ NMR $\left(126 \mathrm{MHz}\right.$, Acetone- $\left.d_{6}\right) \delta$ 181.4, 158.5, 150.2, 148.7, 147.1, 143.8, 138.9, 137.1, 135.3, 135.0, 131.6, 131.3, $128.6,127.9,127.7,126.0,125.5,125.4,124.4,123.9,120.5,119.3,117.2,117.1,116.0,114.7,108.8,106.2,71.3$, $21.5,16.6$.

IR (neat): 3208 (broad), 2359, 1707, $1598 \mathrm{~cm}^{-1}$. HRMS (ESI-TOF) m/z: [(M+H)+] calcd for $\left(\mathrm{C}_{26} \mathrm{H}_{18} \mathrm{Br}_{2} \mathrm{~N}_{7} \mathrm{O}+\right)$ 756.0028, 757.0057, 758.0010, 759.0037, 759.9996, 761.0018, 762.0012. Found: 756.0023, 757.0052, 758.0013, 759.0033, 759.9991, 761.0014, 762.0009. m.p.: decomposed at $>200^{\circ} \mathrm{C}$.
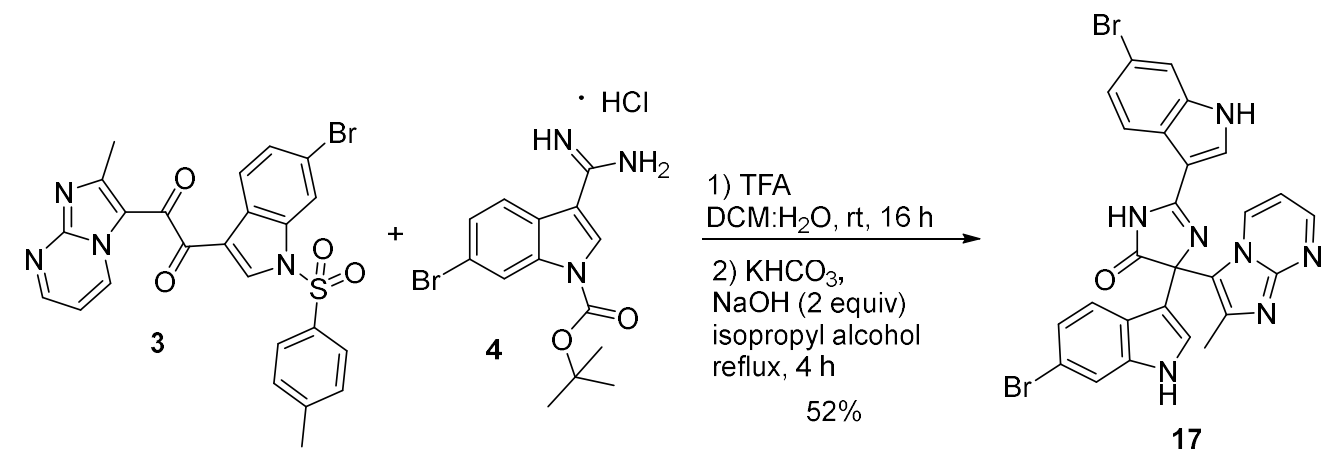

2,5-bis(6-bromo-1H-indol-3-yl)-5-(3-methylimidazo[1,2-a]pyrimidin-2-yl)-3,5-dihydro-4H-imidazol-4-one (17): A solution of 4 (22 mg, $0.06 \mathrm{mmol}$ ) in $5 \mathrm{~mL}$ of dichloromethane was added to a clean, dry round bottom flask under nitrogen. Trifluoroacetic acid $(0.3 \mathrm{~mL})$ and a drop of water were added to the reaction. The reaction was then stirred at room temperature for 24 hours. Once complete, the reaction was concentrated in vacuo. Once dry, the residue was dissolved in $5 \mathrm{~mL}$ isopropyl alcohol and potassium bicarbonate $(76 \mathrm{mg}, 0.75 \mathrm{mmol}$ ) was added to the reaction. Sodium hydroxide $(2.3 \mathrm{mg}, 0.06 \mathrm{mmol})$ was then added to the reaction, bringing the $\mathrm{pH}$ of the reaction from 1 to 8 . Once the reaction turned alkaline, 3 (26 mg, $0.05 \mathrm{mmol})$ was added to the reaction. The reaction was refluxed via heating mantle overnight. Three more equivalents of sodium hydroxide were added, and the reaction was refluxed via heating mantle for 
another 2 hours. Once the reaction was complete based on TLC, the crude mixture was concentrated in vacuo, and the product was purified using automated CombiFlash chromatography (silica gel, 20-40 microns, dichloromethane/methanol gradient $0-10 \%$ ) to give a brown solid (15 mg, 46-52\% yield).

${ }^{1} \mathrm{H}$ NMR $(500 \mathrm{MHz}$, DMSO-d 6 ) $\delta 12.01$ (s, br., 1H), 11.92 (s, br., 1H), 11.43 (s, br., 1H), 8.68 (dd, J = 7.0, 2.0 Hz, 1H), 8.40 (ddd, $J=6.2,4.1,2.0 \mathrm{~Hz}, 1 \mathrm{H}), 8.24(\mathrm{~d}, J=8.6 \mathrm{~Hz}, 1 \mathrm{H}), 8.18(\mathrm{~d}, J=2.3 \mathrm{~Hz}, 1 \mathrm{H}), 7.73(\mathrm{~d}, J=1.8 \mathrm{~Hz}, 1 \mathrm{H}), 7.57(\mathrm{~d}, J$ $=1.8 \mathrm{~Hz}, 1 \mathrm{H}), 7.37(\mathrm{~d}, J=2.6 \mathrm{~Hz}, 1 \mathrm{H}), 7.32(\mathrm{dd}, J=8.6,1.8 \mathrm{~Hz}, 1 \mathrm{H}), 7.12(\mathrm{~d}, J=8.6 \mathrm{~Hz}, 1 \mathrm{H}), 7.05-6.99(\mathrm{~m}, 1 \mathrm{H}), 6.84$ (dd, $J=7.0,4.2 \mathrm{~Hz}, 1 \mathrm{H}), 2.54(\mathrm{~s}, 3 \mathrm{H})$.

${ }^{13} \mathrm{C}$ NMR $(126 \mathrm{MHz}$, DMSO-d 6 ) $\delta$ 182.0, 156.4, 149.2, 147.0, 141.9, 137.8, 137.7, 134.1, 130.9, 124.8, 124.3, 124.2, 124.1, 123.1, 122.2, 120.8, 115.6, 115.0, 114.5, 114.5, 111.4, 107.7, 104.8, 104.5, 70.8, 16.1.

IR (neat): 3174, 3101 (broad), 2923, 2844, $1611 \mathrm{~cm}^{-1}$. HRMS (ESI-TOF) m/z: [(M+H) $\left.{ }^{+}\right]$calcd for $\left(\mathrm{C}_{26} \mathrm{H}_{18} \mathrm{Br}_{2} \mathrm{~N}_{7} \mathrm{O}+\right)$ 601.9940, 602.9968, 603.9921, 604.9948, 605.9905. Found: 601.9947, 602.9975, 603.9929, 604.9955, 605.9913. m.p.: $208^{\circ} \mathrm{C}$.
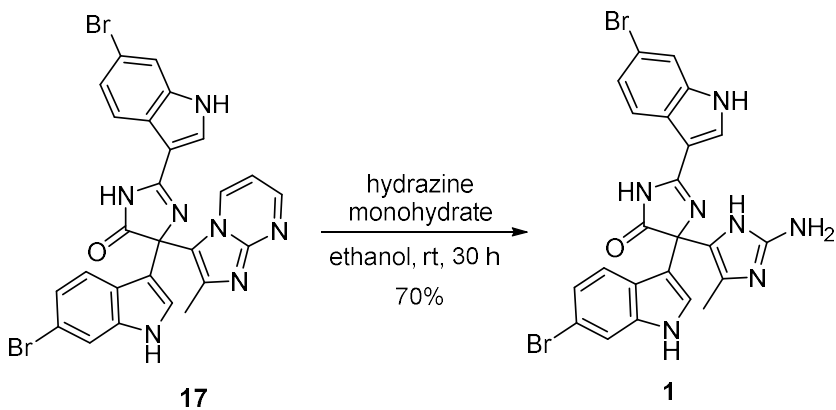

2-amino-2',4'-bis(6-bromo-1H-indol-3-yl)-5-methyl-1',4'-dihydro-1H,5'H-[4,4'-biimidazol]-5'-one (1): 17 (47 mg, 0.08 $\mathrm{mmol}$ ) was added to a clean, dry round bottom flask under nitrogen and dissolved in $2.5 \mathrm{~mL}$ of ethanol. Hydrazine monohydrate $(5 \mathrm{~mL})$ was then added to the reaction. The reaction was stirred at room temperature for 30 hours. Once the reaction was complete as determined by TLC, the solution was concentrated in vacuo. The crude product was purified using automated CombiFlash chromatography (C18 derivatized silica, 20-40 microns, water/methanol gradient $0-100 \%)$ to give a yellow to red solid (31 $\mathrm{mg}, 70 \%$ yield).

${ }^{1} \mathrm{H}$ NMR (500 MHz, DMSO-d 6 ) (NMR taken with stoichiometric amount of TFA) $\delta 12.10$ (s, br., $1 \mathrm{H}$ ), 11.99 (s, br., 1H), $11.26(\mathrm{~m}, \mathrm{br} ., 2 \mathrm{H}), 8.28(\mathrm{~d}, J=8.5 \mathrm{~Hz}, 1 \mathrm{H}), 8.23(\mathrm{~s}, 1 \mathrm{H}), 7.73(\mathrm{~d}, J=1.8 \mathrm{~Hz}, 1 \mathrm{H}), 7.61(\mathrm{~d}, J=1.8 \mathrm{~Hz}, 1 \mathrm{H}), 7.55(\mathrm{~d}, J=$ $8.3 \mathrm{~Hz}, 1 \mathrm{H}$ ), 7.34 (dd, $J=8.5,2.1 \mathrm{~Hz}, 2 \mathrm{H}), 7.14$ (dd, $J=8.6,1.8 \mathrm{~Hz}, 1 \mathrm{H}), 6.93$ (s, br., $2 \mathrm{H}$ ), 2.03 (s, 3H).

${ }^{13} \mathrm{C}$ NMR (126 MHz, DMSO-d $)$ (Apodization set to exponential $=8 \mathrm{~Hz}$ for broad peaks) $\delta 182.6$ (br.), 158.5 (br.), 145.9 , $137.5,137.4,131.0,124.6,124.1,124.0,123.9,122.9,121.8,121.1,119.3,118.6,115.2,114.6,114.2,114.1,111.8$, 104.6, 67.7 (br.), 9.2.

IR (neat): 3722, 3633, 3225 (broad), 2924, 2359, 1685, 1559, $1449 \mathrm{~cm}^{-1}$. HRMS (ESI-TOF) m/z: [(M+H)+] calcd for $\left(\mathrm{C}_{23} \mathrm{H}_{18} \mathrm{Br}_{2} \mathrm{~N}_{7} \mathrm{O}^{+}\right)$565.9940, 566.9968, 567.9921, 568.9948, 569.9904, 570.9929 Found: 565.9953, 566.9979, 567.9937, 568.9966, 569.9926, 570.9950. m.p.: decomposed at $160^{\circ} \mathrm{C}$. 
Table S1. Tabulated spectral comparison of nortopsentin $D(1)$ to isolated natural product.

\begin{tabular}{|c|c|c|}
\hline Spectrum & nortopsentin D (1) & Isolated natural product \\
\hline${ }^{1} \mathrm{H}$ NMR (ppm in DMSO- $\left.d_{6}\right)$ & $\begin{array}{l}\delta 12.10(\mathrm{~s}, \mathrm{br} ., 1 \mathrm{H}), 11.99(\mathrm{~s}, \mathrm{br} ., \\
1 \mathrm{H}), 11.26(\mathrm{~s}, \mathrm{br} ., 2 \mathrm{H}), 8.28(\mathrm{~d}, J= \\
8.5 \mathrm{~Hz}, 1 \mathrm{H}), 8.23(\mathrm{~s}, 1 \mathrm{H}), 7.73(\mathrm{~d}, J= \\
1.8 \mathrm{~Hz}, 1 \mathrm{H}), 7.61(\mathrm{~d}, J=1.8 \mathrm{~Hz}, 1 \mathrm{H}), \\
7.55(\mathrm{~d}, J=8.3 \mathrm{~Hz}, 1 \mathrm{H}), 7.34(\mathrm{~d}, \mathrm{~d}, J \\
=8.5,2.1 \mathrm{~Hz}, 2 \mathrm{H}), 7.14(\mathrm{dd}, J=8.6, \\
1.8 \mathrm{~Hz}, 1 \mathrm{H}), 6.93(\mathrm{~s}, \mathrm{br} ., 2 \mathrm{H}), 2.03(\mathrm{~s}, \\
3 \mathrm{H}) .\end{array}$ & $\begin{array}{l}\delta 12.93(\mathrm{~s}, \mathrm{br}, 1 \mathrm{H}), 12.09(\mathrm{~s}, \mathrm{br}, 1 \mathrm{H}), \\
11.43(\mathrm{~s}, \mathrm{br}, 1 \mathrm{H}), 8.35(\mathrm{~s}, 1 \mathrm{H}), 8.26 \\
(\mathrm{~d}, \mathrm{~J}=8.7 \mathrm{~Hz}, 1 \mathrm{H}), 7.75(\mathrm{~d}, \mathrm{~J}=1.5 \\
\mathrm{Hz}, 1 \mathrm{H}), 7.62(\mathrm{~d}, \mathrm{~J}=1.8 \mathrm{~Hz}, 1 \mathrm{H}), \\
7.50(\mathrm{~d}, \mathrm{~J}=8.7 \mathrm{~Hz}, 1 \mathrm{H}), 7.41(\mathrm{~d}, \mathrm{~J}= \\
2.7 \mathrm{~Hz}, 1 \mathrm{H}), 7.39(\mathrm{dd}, \mathrm{J}=8.7,1 \mathrm{H}), \\
7.16(\mathrm{dd}, \mathrm{J}=8.7,1.8 \mathrm{~Hz}, 1 \mathrm{H}), 7.05 \\
(\mathrm{~s}, \mathrm{br}, 2 \mathrm{H}), 1.95(\mathrm{~s}, 3 \mathrm{H}) .\end{array}$ \\
\hline${ }^{13} \mathrm{C}$ NMR (ppm in DMSO- $d_{6}$ ) & $\begin{array}{l}\delta 182.6 \text { (br.), } 158.5 \text { (br.), 145.9, } \\
\text { 137.5, 137.4, 131.0, 124.6, 124.1, } \\
\text { 124.0, 123.9, 122.9, 121.8, 121.1, } \\
\text { 119.3, 118.6, 115.2, 114.6, 114.2, } \\
114.1,111.8,104.6,67.7 \text { (br.), 9.2. }\end{array}$ & $\begin{array}{l}\delta 181.62,156.75,145.98,137.62 \\
137.58,130.92,124.49,124.39 \\
124.04,123.96,123.15,121.95 \\
121.43,119.23,118.74,115.35 \\
114.82,114.36,114.24,112.06 \\
104.78,69.36,9.53 .\end{array}$ \\
\hline Mass Spectroscopy & $\begin{array}{l}\text { HRMS (ESI-TOF) m/z [M+H]: } \\
565.9953,566.9979,567.9937 \\
568.9966,569.9926,570.9950 .\end{array}$ & $\begin{array}{l}\text { FAB-MS (glycerol, } \mathrm{H}^{+} \text {, matrix): } 566 \text {, } \\
568,570\end{array}$ \\
\hline
\end{tabular}




\section{Crystallographic analysis}

Crystal structure was performed at $265 \mathrm{~K}$. Attempts to collect data at the standard $100 \mathrm{~K}$ results in the crystal crumbling and or disintegrated.

Figure S1. X-ray crystal structure of cyclized imidazol-4-one containing product 17 , thermal ellipsoids shown with $50 \%$ probability.

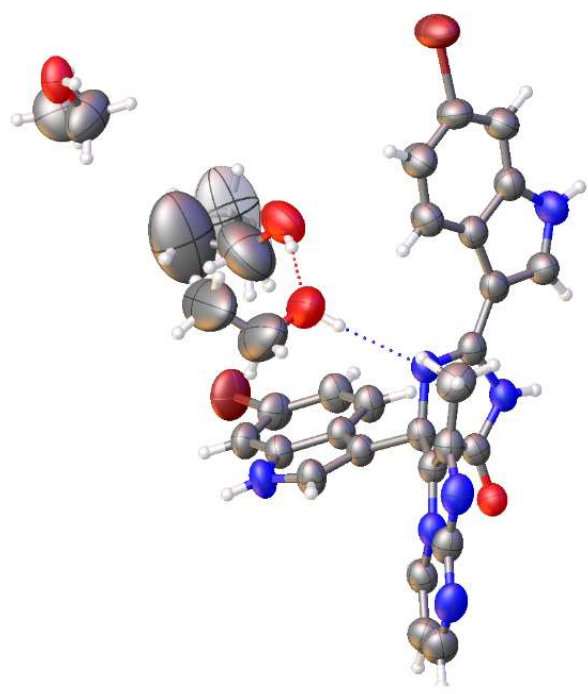

Experimental. Single colourless needle-shaped crystals of JJT521A were recrystallized using a solvent system of ethanol and dichloromethane. The solvent was allowed to slowly evaporate from a siliconized, rubber topped vial (a needle was inserted into the lid to allow for evaporation) and stored at $0{ }^{\circ} \mathrm{C}$ over a period of several week. A suitable crystal with dimensions $0.29 \times 0.05 \times 0.02 \mathrm{~mm}^{3}$ was selected and mounted on a nylon loop with paratone oil on a XtaLAB Synergy, Dualflex, HyPix diffractometer. The crystal was kept at a steady $T=264.99(10) \mathrm{K}$ during data collection. The structure was solved with the ShelXT 2018/3 (Sheldrick, G.M. (2015). Acta Cryst. A71, 3-8) solution program using dual methods and by using $O$. V. Dolomanov, L. J. Bourhis, R. J. Gildea, J. A. K. Howard and H. Puschmann,Olex2: a complete structure solution, refinement and analysis program.J. Appl. Cryst. (2009). 42, 339-341. as the graphical interface. The model was refined with ShelXL (Sheldrick, Acta Cryst. A64 2008, 112-122) using full matrix least squares minimisation on $\boldsymbol{F}^{2}$. Crystal Data. $\mathrm{C}_{32} \mathrm{H}_{35} \mathrm{Br}_{2} \mathrm{~N}_{7} \mathrm{O}_{4}, M_{r}=741.49$, triclinic, $P-1$ (No. 2), $\mathrm{a}=$ 10.7492(5) $\AA, b=12.1864(6) \AA, c=13.7951(5) \AA, a=81.742(3)^{\circ}, b=$ 88.748(4) $)^{\circ}, g=76.808(4)^{\circ}, V=1741.01(14) \AA^{3}, T=264.99(10) \mathrm{K}, Z=$ $2, Z^{\prime}=1, m\left(\mathrm{Cu} \mathrm{K}_{a}\right)=3.323,23996$ reflections measured, 7304 unique $\left(R_{\text {int }}=0.0753\right)$ which were used in all calculations. The final $w R_{2}$ was 0.2470 (all data) and $R_{1}$ was $0.0805(\mathrm{I} \geq 2 s(\mathrm{I}))$.

\begin{tabular}{|c|c|}
\hline Compound & JJT521A \\
\hline Formula & $\mathrm{C}_{32} \mathrm{H}_{35} \mathrm{Br}_{2} \mathrm{~N}_{7} \mathrm{O}_{4}$ \\
\hline CCDC & 2081971 \\
\hline Dcalc & 1.414 \\
\hline $\mathrm{m} / \mathrm{mm}^{-1}$ & 3.323 \\
\hline Formula Weight & 741.49 \\
\hline Colour & colourless \\
\hline Shape & needle-shaped \\
\hline Size $/ \mathrm{mm}^{3}$ & $0.29 \times 0.05 \times 0.02$ \\
\hline$T / \mathrm{K}$ & $264.99(10)$ \\
\hline Crystal System & triclinic \\
\hline Space Group & $P-1$ \\
\hline alA & $10.7492(5)$ \\
\hline$b / \AA$ & 12.1864(6) \\
\hline$c / \AA ̊$ & 13.7951(5) \\
\hline$a l^{\circ}$ & $81.742(3)$ \\
\hline$b l^{\circ}$ & $88.748(4)$ \\
\hline$g f^{\circ}$ & $76.808(4)$ \\
\hline$V / \AA^{3}$ & $1741.01(14)$ \\
\hline$z$ & 2 \\
\hline$Z^{\prime}$ & 1 \\
\hline Wavelength/Å & 1.54184 \\
\hline Radiation type & $\mathrm{Cu} \mathrm{Ka}$ \\
\hline$Q_{\min } l^{\circ}$ & 3.237 \\
\hline$Q_{\max } l^{\circ}$ & 80.271 \\
\hline Measured Refl's. & 23996 \\
\hline Indep't Refl's & 7304 \\
\hline Refl's $I \geq 2 s(I)$ & 4911 \\
\hline$R_{\text {int }}$ & 0.0753 \\
\hline Parameters & 418 \\
\hline Restraints & 1 \\
\hline Largest Peak & 1.361 \\
\hline Deepest Hole & -0.953 \\
\hline GooF & 1.049 \\
\hline$w R_{2}$ (all data) & 0.2470 \\
\hline$w R_{2}$ & 0.2192 \\
\hline$R_{1}$ (all data) & 0.1100 \\
\hline$R_{1}$ & 0.0805 \\
\hline
\end{tabular}


Structure Quality Indicators Reflections:

\begin{tabular}{|c|c|c|c|c|c|c|c|}
\hline $\begin{array}{l}d \min (C u \backslash a) \\
2 \Theta=160.5^{\circ}\end{array}$ & 0.78 & $1 / \sigma(1)$ & 13.5 & Rint & $7.53 \%$ & $\begin{array}{l}\text { CAP } 148.7^{\circ} \\
96 \% \text { to } 160.5^{\circ}\end{array}$ & 98.4 \\
\hline Shift & 001 & Max Peak & 1.4 & Min Peak & -0.9 & GooF & \\
\hline
\end{tabular}

A colourless needle-shaped-shaped crystal with dimensions $0.29 \times 0.05 \times 0.02 \mathrm{~mm}^{3}$ was mounted on a nylon loop with paratone oil. Data were collected using a XtaLAB Synergy, Dualflex, HyPix diffractometer equipped with an Oxford Cryosystems low-temperature device, operating at $T=264.99(10) \mathrm{K}$.

MSU Data were measured using $w$ scans using $\mathrm{Cu} \mathrm{K}_{a}$ radiation (micro-focus sealed X-ray tube, $50 \mathrm{kV}, 1 \mathrm{~mA}$ ). The total number of runs and images was based on the strategy calculation from the program CrysAlisPro (Rigaku, V1.171.41.108a, 2021). The actually achieved resolution was $Q=80.271$.

Cell parameters were retrieved using the CrysAlisPro (Rigaku, V1.171.41.108a, 2021) software and refined using CrysAlisPro (Rigaku, V1.171.41.108a, 2021) on 5194 reflections, $22 \%$ of the observed reflections. Data reduction was performed using the CrysAlisPro (Rigaku, V1.171.41.108a, 2021) software which corrects for Lorentz polarization. The final completeness is 99.30 out to 80.271 in Q CrysAlisPro 1.171.41.108a (Rigaku Oxford Diffraction, 2021) Numerical absorption correction based on gaussian integration over a multifaceted crystal model. Empirical absorption correction using spherical harmonics, implemented in SCALE3 ABSPACK scaling algorithm.

The structure was solved in the space group P-1 (\# 2) by using dual methods using the ShelXT 2018/3 (Sheldrick, G.M. (2015). Acta Cryst. A71, 3-8) structure solution program. The structure was refined by Least Squares ShelXL incorporated in Olex2 software program. All non-hydrogen atoms were refined anisotropically. Hydrogen atom positions were calculated geometrically and refined using the riding model. Hydrogen atoms on the non-carbon atom(s) were determined by observing the residual electron density and then generating a riding model for the hydrogen atoms in those locations.

CCDC 2081971 contains the supplementary crystallographic data for this paper. The data can be obtained free of charge from The Cambridge Crystallographic Data Centre via www.ccdc.cam.ac.uk/structures.

There is a single molecule in the asymmetric unit, which is represented by the reported sum formula. In other words: $Z$ is 2 and $Z^{\prime}$ is 1.

Figure S2: The following hydrogen bonding interactions with a maximum $D-D$ distance of $3.1 \AA$ and a minimum angle of $110^{\circ}$ are present in JJT521A: N2-01_1: 2.794 A, N6-O2_3: 2.9 A, N7-O4_2: 2.819 A, C9-01: 2.923 $A, 02-N 3 \_4$ :

$2.837 \AA$, O3-N1: $2.921 \AA$, O4-O3: $2.711 \AA$., thermal ellipsoids shown with $50 \%$ probability.

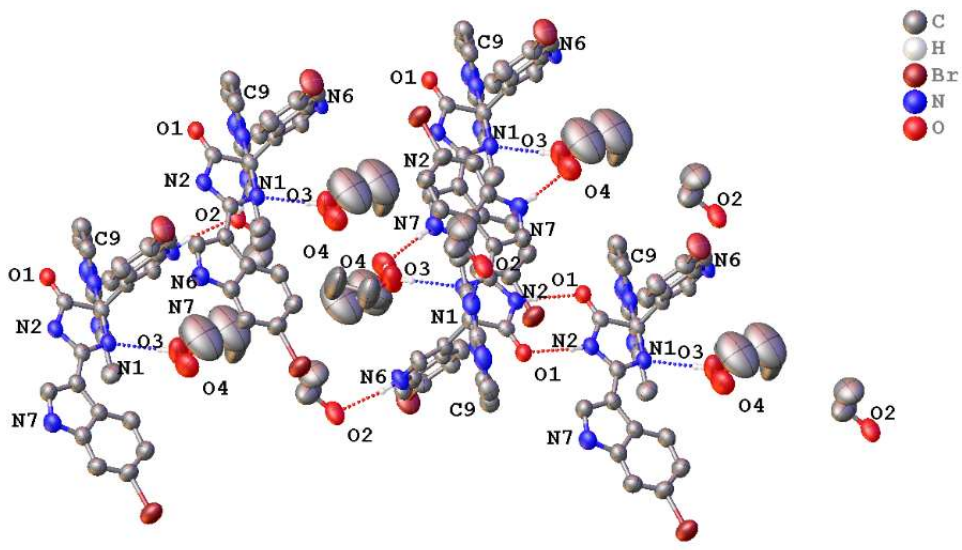


Figure S3: Packing diagram of JJT521A, thermal ellipsoids shown with 50\% probability.

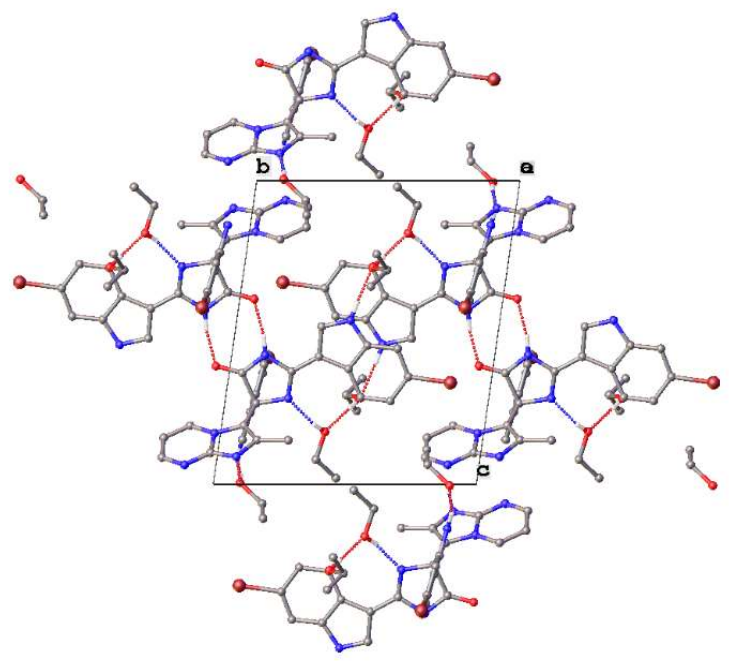

Data Plots: Diffraction Data
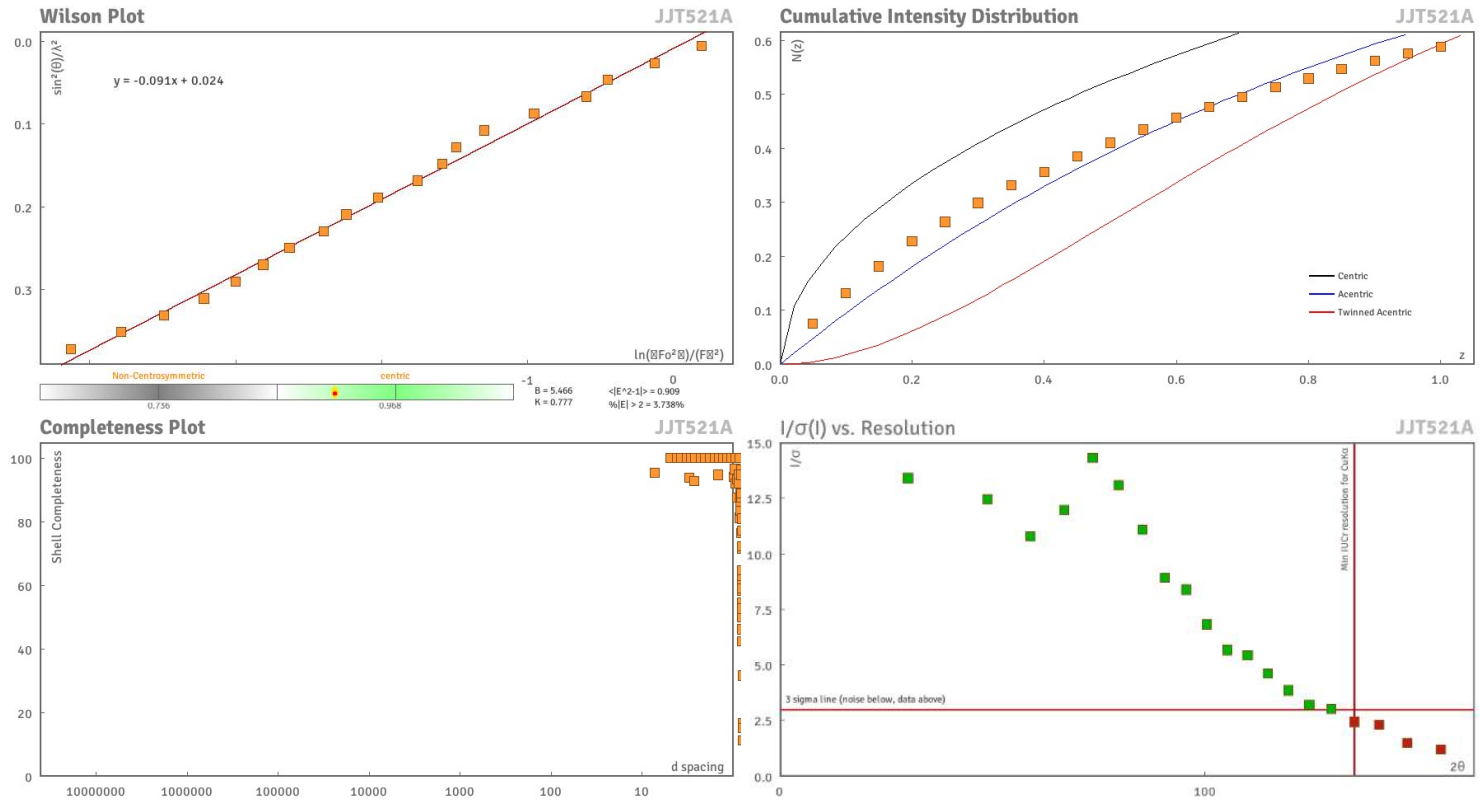

\section{Data Plots: Refinement and Data}
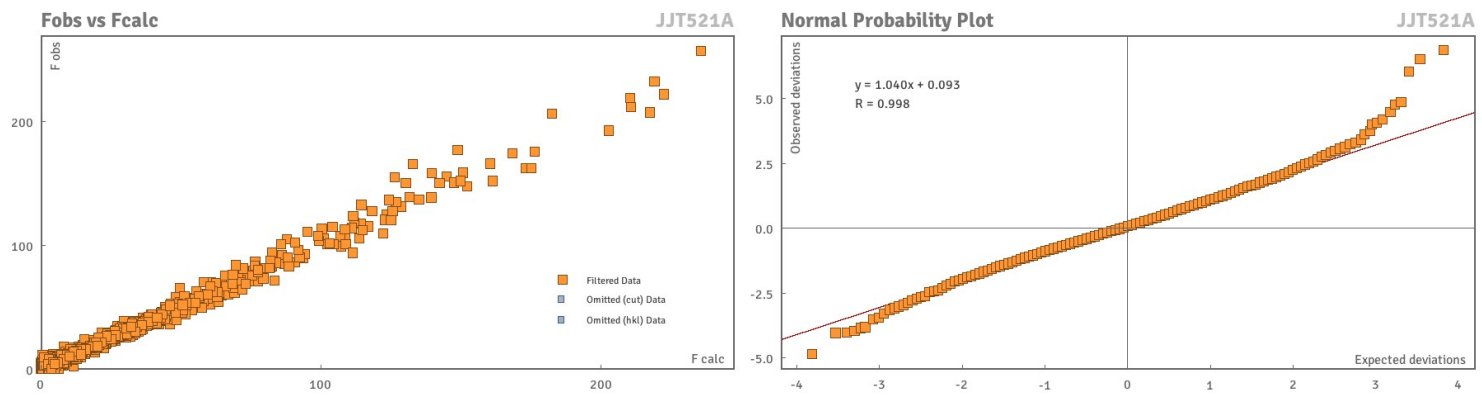
Table S2: Fractional Atomic Coordinates $\left(\times 10^{4}\right)$ and Equivalent Isotropic Displacement Parameters $\left(\AA^{2} \times 10^{3}\right)$ for JJT521A. $U_{e q}$ is defined as $1 / 3$ of the trace of the orthogonalised $U_{i j}$.

\begin{tabular}{|c|c|c|c|c|}
\hline Atom & $x$ & $y$ & z & $U_{\text {eq }}$ \\
\hline$\overline{\mathrm{Br} 1}$ & $2654.3(10)$ & $8456.8(6)$ & $3344.6(6)$ & $95.7(3)$ \\
\hline $\mathrm{Br} 2$ & $12032.6(6)$ & $1401.7(9)$ & $4172.2(6)$ & $93.9(3)$ \\
\hline 01 & $5820(3)$ & $-542(3)$ & $3893(2)$ & $52.8(7)$ \\
\hline N1 & $5225(4)$ & 2376(3) & $2825(3)$ & $47.9(8)$ \\
\hline N2 & 5053(4) & 1270(3) & $4256(3)$ & $47.7(8)$ \\
\hline N3 & $3326(4)$ & $725(5)$ & $906(3)$ & $62.4(11)$ \\
\hline $\mathrm{N} 4$ & 4111(5) & $-1199(5)$ & $638(3)$ & $67.4(12)$ \\
\hline N5 & $5138(4)$ & $-234(4)$ & $1677(3)$ & 49.9(9) \\
\hline N6 & $8869(4)$ & $865(4)$ & $1465(3)$ & $59.3(10)$ \\
\hline N7 & $3495(5)$ & 4316(4) & $5400(3)$ & $63.0(11)$ \\
\hline C1 & 5723(4) & 1180(4) & 2662(3) & $47.3(9)$ \\
\hline $\mathrm{C} 2$ & $5571(4)$ & $489(4)$ & $3668(3)$ & $45.1(9)$ \\
\hline C3 & $4864(4)$ & $2362(4)$ & $3719(3)$ & $48.4(10)$ \\
\hline C4 & 4888(4) & $851(4)$ & 1934(3) & $47.0(9)$ \\
\hline C5 & $3755(5)$ & 1419(5) & $1458(3)$ & $53.2(11)$ \\
\hline C6 & $4160(5)$ & $-268(5)$ & 1039(4) & $55.2(11)$ \\
\hline $\mathrm{C} 7$ & $5037(6)$ & $-2095(6)$ & $880(5)$ & $71.9(15)$ \\
\hline C8 & $6049(6)$ & $-2136(6)$ & 1529(4) & $67.2(14)$ \\
\hline C9 & $6087(5)$ & $-1199(5)$ & 1930(4) & $55.9(11)$ \\
\hline C10 & $3017(6)$ & $2611(6)$ & $1447(5)$ & $72.6(15)$ \\
\hline C11 & 7103(4) & 1016(4) & $2365(3)$ & $46.6(9)$ \\
\hline C12 & $8129(4)$ & 1118(4) & 2968(3) & $47.5(10)$ \\
\hline $\mathrm{C} 13$ & $8261(5)$ & $1273(5)$ & $3947(4)$ & $57.1(12)$ \\
\hline C14 & $9409(5)$ & $1357(6)$ & $4281(4)$ & $63.0(13)$ \\
\hline C15 & 10451(5) & $1273(5)$ & $3659(4)$ & $61.5(13)$ \\
\hline C16 & 10393(5) & 1104(5) & 2710(4) & $58.1(12)$ \\
\hline C17 & $9231(4)$ & 1017(4) & 2371(4) & $50.8(10)$ \\
\hline C18 & 7601(5) & $869(5)$ & $1465(4)$ & $56.3(11)$ \\
\hline C19 & $4308(5)$ & $3327(4)$ & 4206(4) & $51.8(10)$ \\
\hline C20 & $3942(5)$ & $4508(4)$ & $3803(4)$ & $52.3(10)$ \\
\hline C21 & 3964(5) & $5128(5)$ & 2863(4) & $60.9(12)$ \\
\hline C22 & $3541(6)$ & 6276(5) & $2745(5)$ & $68.4(14)$ \\
\hline $\mathrm{C} 23$ & $3118(6)$ & 6829(5) & $3541(4)$ & $63.9(13)$ \\
\hline C24 & $3031(6)$ & $6270(5)$ & $4465(4)$ & $62.6(13)$ \\
\hline C25 & $3451(5)$ & 5099(5) & $4571(4)$ & $56.8(11)$ \\
\hline C26 & 4003(5) & $3265(5)$ & 5193(4) & $57.7(11)$ \\
\hline $\mathrm{O} 2$ & $9122(4)$ & 8989(5) & $-47(3)$ & $76.7(12)$ \\
\hline C27 & $9415(8)$ & $8034(10)$ & $643(10)$ & $122(3)$ \\
\hline $\mathrm{C} 28$ & 10623(11) & $7924(12)$ & 1129(9) & $140(4)$ \\
\hline O3 & 6595(9) & $3958(6)$ & $1728(6)$ & $128(3)$ \\
\hline C29 & $6942(18)$ & $3764(11)$ & $811(9)$ & $160(6)$ \\
\hline C30 & $7360(20)$ & $4627(13)$ & 204(12) & $225(11)$ \\
\hline O4 & $7718(7)$ & $5124(6)$ & 2846(5) & $113(2)$ \\
\hline C31 & $9023(17)$ & $4561(17)$ & 2942(14) & $186(7)$ \\
\hline C32 & $9780(30)$ & $5090(40)$ & $3480(30)$ & $280(20)$ \\
\hline C33 & $9980(50)$ & $5040(70)$ & $2420(50)$ & $280(20)$ \\
\hline
\end{tabular}


Table S3: Anisotropic Displacement Parameters $\left(\times 10^{4}\right)$ for JJT521A. The anisotropic displacement factor exponent takes the form: $-2 p^{2}\left[h^{2} a^{* 2} \times U_{11}+\ldots+2 h k a^{*} \times b^{*} \times U_{12}\right]$

\begin{tabular}{|c|c|c|c|c|c|c|}
\hline Atom & $U_{11}$ & $U_{22}$ & $U_{33}$ & $U_{23}$ & $U_{13}$ & $U_{12}$ \\
\hline $\mathrm{Br} 1$ & $138.7(8)$ & $57.8(4)$ & $83.1(5)$ & $-7.2(3)$ & $15.3(5)$ & $-10.1(4)$ \\
\hline $\mathrm{Br} 2$ & 54.3(4) & $138.8(8)$ & $99.0(6)$ & $-16.9(5)$ & $-16.3(3)$ & $-41.9(4)$ \\
\hline $\mathrm{O} 1$ & $56.3(18)$ & $56(2)$ & $46.0(17)$ & $-6.3(14)$ & $5.6(14)$ & $-14.4(14)$ \\
\hline N1 & $47.8(19)$ & $54(2)$ & $43.4(19)$ & $-7.2(16)$ & $3.3(15)$ & $-15.1(16)$ \\
\hline N2 & $44.5(18)$ & $57(2)$ & $42.9(19)$ & $-7.7(16)$ & $3.9(15)$ & $-13.5(16)$ \\
\hline N3 & $52(2)$ & $87(3)$ & $52(2)$ & $-4(2)$ & $-8.8(18)$ & $-27(2)$ \\
\hline N4 & $73(3)$ & $89(4)$ & $54(2)$ & $-19(2)$ & $3(2)$ & $-41(3)$ \\
\hline N5 & $45.4(19)$ & $67(2)$ & $41.0(19)$ & $-9.3(17)$ & $0.3(15)$ & $-19.3(17)$ \\
\hline N6 & $48(2)$ & $86(3)$ & $49(2)$ & $-18(2)$ & $12.0(17)$ & $-23(2)$ \\
\hline N7 & $76(3)$ & $65(3)$ & $49(2)$ & $-13.5(19)$ & $10(2)$ & $-15(2)$ \\
\hline C1 & $42(2)$ & $63(3)$ & $39(2)$ & $-11.3(19)$ & $0.2(16)$ & $-15.9(18)$ \\
\hline $\mathrm{C} 2$ & $36.6(19)$ & $57(3)$ & $44(2)$ & $-11.0(19)$ & $-2.9(16)$ & $-13.0(17)$ \\
\hline C3 & $42(2)$ & $59(3)$ & $47(2)$ & $-8.1(19)$ & $-0.2(17)$ & $-16.8(18)$ \\
\hline C4 & $44(2)$ & $59(3)$ & $41(2)$ & $-5.8(18)$ & $-1.6(17)$ & $-16.9(18)$ \\
\hline C5 & $47(2)$ & $69(3)$ & $45(2)$ & $-2(2)$ & $-3.3(18)$ & $-19(2)$ \\
\hline C6 & $54(3)$ & $74(3)$ & $45(2)$ & $-9(2)$ & $-4.5(19)$ & $-29(2)$ \\
\hline C7 & $77(4)$ & $79(4)$ & $72(4)$ & $-25(3)$ & $5(3)$ & $-33(3)$ \\
\hline C8 & $74(3)$ & $70(3)$ & $63(3)$ & $-19(3)$ & $6(3)$ & $-21(3)$ \\
\hline C9 & $53(3)$ & $68(3)$ & $50(2)$ & $-14(2)$ & $4(2)$ & $-17(2)$ \\
\hline C10 & $62(3)$ & $75(4)$ & $76(4)$ & $2(3)$ & $-17(3)$ & $-14(3)$ \\
\hline C11 & $42(2)$ & $56(2)$ & $45(2)$ & $-10.4(19)$ & $2.1(17)$ & $-17.1(18)$ \\
\hline C12 & $40(2)$ & $57(3)$ & $48(2)$ & $-8.8(19)$ & $0.5(17)$ & $-14.2(18)$ \\
\hline C13 & $51(2)$ & $77(3)$ & $49(3)$ & $-13(2)$ & $0(2)$ & $-23(2)$ \\
\hline C14 & $48(3)$ & $87(4)$ & $58(3)$ & $-16(3)$ & $-7(2)$ & $-21(2)$ \\
\hline C15 & $42(2)$ & $74(3)$ & $73(3)$ & $-12(3)$ & $-10(2)$ & $-19(2)$ \\
\hline C16 & $41(2)$ & $69(3)$ & $66(3)$ & $-7(2)$ & $4(2)$ & $-18(2)$ \\
\hline C17 & $45(2)$ & $60(3)$ & $49(2)$ & $-8(2)$ & $4.0(18)$ & $-13.8(19)$ \\
\hline C18 & $51(2)$ & $78(3)$ & $45(2)$ & $-13(2)$ & $3.2(19)$ & $-24(2)$ \\
\hline C19 & $48(2)$ & $60(3)$ & $52(3)$ & $-14(2)$ & $5.9(19)$ & $-18(2)$ \\
\hline $\mathrm{C} 20$ & $48(2)$ & $58(3)$ & $52(3)$ & $-10(2)$ & $5.0(19)$ & $-14(2)$ \\
\hline C21 & $64(3)$ & $67(3)$ & $52(3)$ & $-13(2)$ & $6(2)$ & $-14(2)$ \\
\hline $\mathrm{C} 22$ & $78(4)$ & $61(3)$ & $60(3)$ & $-2(2)$ & $6(3)$ & $-10(3)$ \\
\hline $\mathrm{C} 23$ & $76(3)$ & $49(3)$ & $66(3)$ & $-11(2)$ & $3(3)$ & $-12(2)$ \\
\hline C24 & $67(3)$ & $57(3)$ & $62(3)$ & $-13(2)$ & $5(2)$ & $-9(2)$ \\
\hline C25 & $58(3)$ & $62(3)$ & $54(3)$ & $-11(2)$ & $7(2)$ & $-18(2)$ \\
\hline $\mathrm{C} 26$ & $68(3)$ & $56(3)$ & $50(3)$ & $-8(2)$ & $6(2)$ & $-16(2)$ \\
\hline $\mathrm{O} 2$ & $51(2)$ & $115(4)$ & $65(2)$ & $-7(2)$ & $0.4(18)$ & $-26(2)$ \\
\hline $\mathrm{C} 27$ & $72(5)$ & $117(7)$ & $168(10)$ & $19(7)$ & $-16(5)$ & $-28(4)$ \\
\hline $\mathrm{C} 28$ & $113(8)$ & 164(11) & $125(8)$ & $2(8)$ & $-37(6)$ & $-6(7)$ \\
\hline O3 & $167(7)$ & $98(4)$ & $133(5)$ & $-30(4)$ & $72(5)$ & $-58(4)$ \\
\hline C29 & $255(18)$ & 119(9) & $120(9)$ & $-15(7)$ & $57(10)$ & $-78(11)$ \\
\hline C30 & $370(30)$ & $120(10)$ & $162(13)$ & $13(9)$ & 134(17) & $-38(14)$ \\
\hline O4 & $137(5)$ & $110(4)$ & $90(4)$ & $-29(3)$ & $33(4)$ & $-15(4)$ \\
\hline C31 & 152(13) & 195(17) & 186(16) & $-39(13)$ & $29(12)$ & $15(12)$ \\
\hline C32 & $150(20)$ & $470(60)$ & $240(30)$ & $-90(40)$ & $-30(20)$ & $-100(30)$ \\
\hline C33 & $150(20)$ & $470(60)$ & $240(30)$ & $-90(40)$ & $-30(20)$ & $-100(30)$ \\
\hline
\end{tabular}

Table S4: Bond Lengths in Å for JJT521A.

\begin{tabular}{lll}
\hline Atom & \multicolumn{1}{c}{ Atom } & \multicolumn{1}{c}{ Length/A } \\
\hline $\mathrm{Br} 1$ & $\mathrm{C} 23$ & $1.912(5)$ \\
$\mathrm{Br} 2$ & $\mathrm{C} 15$ & $1.903(5)$ \\
$\mathrm{O} 1$ & $\mathrm{C} 2$ & $1.219(6)$ \\
$\mathrm{N} 1$ & $\mathrm{C} 1$ & $1.481(6)$ \\
$\mathrm{N} 1$ & $\mathrm{C} 3$ & $1.284(6)$ \\
$\mathrm{N} 2$ & $\mathrm{C} 2$ & $1.355(6)$ \\
$\mathrm{N} 2$ & $\mathrm{C} 3$ & $1.401(7)$ \\
$\mathrm{N} 3$ & $\mathrm{C} 5$ & $1.373(7)$ \\
$\mathrm{N} 3$ & $\mathrm{C} 6$ & $1.323(8)$ \\
$\mathrm{N} 4$ & $\mathrm{C} 6$ & $1.344(7)$ \\
$\mathrm{N} 4$ & $\mathrm{C} 7$ & $1.307(9)$ \\
$\mathrm{N} 5$ & $\mathrm{C} 4$ & $1.384(7)$ \\
$\mathrm{N} 5$ & $\mathrm{C} 6$ & $1.397(6)$ \\
$\mathrm{N} 5$ & $\mathrm{C} 9$ & $1.376(7)$ \\
$\mathrm{N} 6$ & $\mathrm{C} 17$ & $1.367(7)$ \\
$\mathrm{N} 6$ & $\mathrm{C} 18$ & $1.362(7)$ \\
$\mathrm{N} 7$ & $\mathrm{C} 25$ & $1.374(7)$ \\
$\mathrm{N} 7$ & $\mathrm{C} 26$ & $1.341(7)$ \\
$\mathrm{C} 1$ & $\mathrm{C} 2$ & $1.542(7)$ \\
$\mathrm{C} 1$ & $\mathrm{C} 4$ & $1.516(6)$
\end{tabular}

\begin{tabular}{lll}
\hline Atom & \multicolumn{1}{c}{ Atom } & \multicolumn{1}{c}{ Length/A } \\
\hline $\mathrm{C} 1$ & $\mathrm{C} 11$ & $1.507(6)$ \\
$\mathrm{C} 3$ & $\mathrm{C} 19$ & $1.443(7)$ \\
$\mathrm{C} 4$ & $\mathrm{C} 5$ & $1.383(7)$ \\
$\mathrm{C} 5$ & $\mathrm{C} 10$ & $1.486(9)$ \\
$\mathrm{C} 7$ & $\mathrm{C} 8$ & $1.411(9)$ \\
$\mathrm{C} 8$ & $\mathrm{C} 9$ & $1.347(8)$ \\
$\mathrm{C} 11$ & $\mathrm{C} 12$ & $1.434(6)$ \\
$\mathrm{C} 11$ & $\mathrm{C} 18$ & $1.361(7)$ \\
$\mathrm{C} 12$ & $\mathrm{C} 13$ & $1.405(7)$ \\
$\mathrm{C} 12$ & $\mathrm{C} 17$ & $1.420(6)$ \\
$\mathrm{C} 13$ & $\mathrm{C} 14$ & $1.357(7)$ \\
$\mathrm{C} 14$ & $\mathrm{C} 15$ & $1.389(8)$ \\
$\mathrm{C} 15$ & $\mathrm{C} 16$ & $1.360(8)$ \\
$\mathrm{C} 16$ & $\mathrm{C} 17$ & $1.374(7)$ \\
$\mathrm{C} 19$ & $\mathrm{C} 20$ & $1.434(8)$ \\
$\mathrm{C} 19$ & $\mathrm{C} 26$ & $1.389(7)$ \\
$\mathrm{C} 20$ & $\mathrm{C} 21$ & $1.406(8)$ \\
$\mathrm{C} 20$ & $\mathrm{C} 25$ & $1.394(7)$ \\
$\mathrm{C} 21$ & $\mathrm{C} 22$ & $1.356(9)$ \\
$\mathrm{C} 22$ & $\mathrm{C} 23$ & $1.385(8)$
\end{tabular}




\begin{tabular}{lll}
\hline Atom & Atom & \multicolumn{1}{c}{ Length/A } \\
\hline $\mathrm{C} 23$ & $\mathrm{C} 24$ & $1.368(8)$ \\
$\mathrm{C} 24$ & $\mathrm{C} 25$ & $1.382(8)$ \\
$\mathrm{O} 2$ & $\mathrm{C} 27$ & $1.373(12)$ \\
$\mathrm{C} 27$ & $\mathrm{C} 28$ & $1.444(14)$ \\
$\mathrm{O} 3$ & $\mathrm{C} 29$ & $1.348(13)$
\end{tabular}

\begin{tabular}{lll}
\hline Atom & \multicolumn{1}{c}{ Atom } & \multicolumn{1}{c}{ Length/A } \\
\hline C29 & C30 & $1.397(17)$ \\
O4 & C31 & $1.414(17)$ \\
C31 & C32 & $1.43(3)$ \\
C31 & C33 & $1.43(3)$
\end{tabular}

Table S5: Bond Angles in ${ }^{\circ}$ for JJT521A.

\begin{tabular}{|c|c|c|c|}
\hline Atom & Atom & Atom & Angle ${ }^{\circ}$ \\
\hline$\overline{\mathrm{C} 3}$ & $\mathrm{~N} 1$ & $\mathrm{C} 1$ & $107.5(4)$ \\
\hline $\mathrm{C} 2$ & N2 & $\mathrm{C} 3$ & $109.2(4)$ \\
\hline C6 & N3 & C5 & $106.5(4)$ \\
\hline $\mathrm{C} 7$ & N4 & $\mathrm{C} 6$ & $116.3(5)$ \\
\hline $\mathrm{C} 4$ & N5 & $\mathrm{C} 6$ & $107.2(4)$ \\
\hline $\mathrm{Cg}$ & N5 & C4 & $133.5(4)$ \\
\hline $\mathrm{C} 9$ & N5 & $\mathrm{C} 6$ & 119.3(4) \\
\hline C18 & N6 & $\mathrm{C} 17$ & $109.5(4)$ \\
\hline $\mathrm{C} 26$ & N7 & $\mathrm{C} 25$ & $110.0(4)$ \\
\hline $\mathrm{N} 1$ & $\mathrm{C} 1$ & $\mathrm{C} 2$ & $103.6(3)$ \\
\hline N1 & $\mathrm{C} 1$ & C4 & $110.8(4)$ \\
\hline $\mathrm{N} 1$ & $\mathrm{C} 1$ & C11 & $109.4(4)$ \\
\hline $\mathrm{C} 4$ & $\mathrm{C} 1$ & $\mathrm{C} 2$ & $107.5(4)$ \\
\hline C11 & $\mathrm{C} 1$ & $\mathrm{C} 2$ & $111.8(4)$ \\
\hline C11 & $\mathrm{C} 1$ & $\mathrm{C} 4$ & $113.4(4)$ \\
\hline O1 & $\mathrm{C} 2$ & N2 & $126.3(4)$ \\
\hline O1 & $\mathrm{C} 2$ & $\mathrm{C} 1$ & $128.2(4)$ \\
\hline N2 & $\mathrm{C} 2$ & $\mathrm{C} 1$ & $105.5(4)$ \\
\hline $\mathrm{N} 1$ & $\mathrm{C} 3$ & N2 & $114.2(4)$ \\
\hline N1 & $\mathrm{C} 3$ & C19 & $127.3(5)$ \\
\hline N2 & $\mathrm{C} 3$ & C19 & $118.4(4)$ \\
\hline N5 & $\mathrm{C} 4$ & $\mathrm{C} 1$ & $121.8(4)$ \\
\hline C5 & $\mathrm{C} 4$ & N5 & $105.3(4)$ \\
\hline $\mathrm{C} 5$ & $\mathrm{C} 4$ & $\mathrm{C} 1$ & $132.7(5)$ \\
\hline N3 & C5 & $\mathrm{C} 4$ & $110.6(5)$ \\
\hline N3 & C5 & $\mathrm{C} 10$ & $119.1(5)$ \\
\hline $\mathrm{C} 4$ & $\mathrm{C} 5$ & $\mathrm{C} 10$ & $130.2(5)$ \\
\hline N3 & $\mathrm{C} 6$ & N4 & $126.7(5)$ \\
\hline N3 & $\mathrm{C} 6$ & N5 & $110.3(4)$ \\
\hline N4 & $\mathrm{C} 6$ & N5 & $123.0(5)$ \\
\hline N4 & $\mathrm{C} 7$ & $\mathrm{C} 8$ & $124.3(6)$ \\
\hline $\mathrm{Cg}$ & $\mathrm{C} 8$ & $\mathrm{C} 7$ & $119.0(6)$ \\
\hline $\mathrm{C} 8$ & $\mathrm{Cg}$ & N5 & $118.2(5)$ \\
\hline $\mathrm{C} 12$ & C11 & $\mathrm{C} 1$ & $125.3(4)$ \\
\hline C18 & $\mathrm{C} 11$ & $\mathrm{C} 1$ & $127.8(4)$ \\
\hline
\end{tabular}

\begin{tabular}{|c|c|c|c|}
\hline Atom & Atom & Atom & Angle $/{ }^{\circ}$ \\
\hline$\overline{\mathrm{C} 18}$ & C11 & C12 & $106.6(4)$ \\
\hline C13 & C12 & C11 & $135.4(4)$ \\
\hline C13 & C12 & C17 & $117.9(4)$ \\
\hline C17 & C12 & C11 & $106.6(4)$ \\
\hline C14 & C13 & C12 & $119.6(5)$ \\
\hline C13 & C14 & C15 & $120.0(5)$ \\
\hline C14 & C15 & $\mathrm{Br} 2$ & $117.9(4)$ \\
\hline C16 & C15 & $\mathrm{Br} 2$ & $118.8(4)$ \\
\hline C16 & C15 & C14 & $123.3(5)$ \\
\hline C15 & C16 & C17 & $116.7(5)$ \\
\hline N6 & C17 & C12 & $107.1(4)$ \\
\hline N6 & C17 & C16 & $130.5(4)$ \\
\hline C16 & C17 & C12 & $122.4(4)$ \\
\hline C11 & C18 & N6 & $110.2(4)$ \\
\hline $\mathrm{C} 20$ & C19 & C3 & $128.9(5)$ \\
\hline $\mathrm{C} 26$ & C19 & C3 & $124.8(5)$ \\
\hline $\mathrm{C} 26$ & C19 & $\mathrm{C} 20$ & $106.3(4)$ \\
\hline $\mathrm{C} 21$ & $\mathrm{C} 20$ & C19 & $134.8(5)$ \\
\hline $\mathrm{C} 25$ & $\mathrm{C} 20$ & C19 & $106.7(4)$ \\
\hline $\mathrm{C} 25$ & $\mathrm{C} 20$ & $\mathrm{C} 21$ & $118.4(5)$ \\
\hline $\mathrm{C} 22$ & $\mathrm{C} 21$ & $\mathrm{C} 20$ & $118.9(5)$ \\
\hline $\mathrm{C} 21$ & $\mathrm{C} 22$ & $\mathrm{C} 23$ & $120.5(6)$ \\
\hline $\mathrm{C} 22$ & $\mathrm{C} 23$ & $\mathrm{Br} 1$ & $118.4(5)$ \\
\hline $\mathrm{C} 24$ & $\mathrm{C} 23$ & $\mathrm{Br} 1$ & $118.3(4)$ \\
\hline $\mathrm{C} 24$ & $\mathrm{C} 23$ & $\mathrm{C} 22$ & $123.3(5)$ \\
\hline $\mathrm{C} 23$ & $\mathrm{C} 24$ & $\mathrm{C} 25$ & $115.5(5)$ \\
\hline N7 & $\mathrm{C} 25$ & $\mathrm{C} 20$ & $107.8(5)$ \\
\hline N7 & $\mathrm{C} 25$ & $\mathrm{C} 24$ & $128.9(5)$ \\
\hline $\mathrm{C} 24$ & $\mathrm{C} 25$ & $\mathrm{C} 20$ & $123.3(5)$ \\
\hline N7 & $\mathrm{C} 26$ & C19 & $109.3(5)$ \\
\hline $\mathrm{O} 2$ & $\mathrm{C} 27$ & $\mathrm{C} 28$ & $112.2(9)$ \\
\hline O3 & $\mathrm{C} 29$ & $\mathrm{C} 30$ & $117.2(12)$ \\
\hline $\mathrm{O} 4$ & C31 & C32 & $114.6(19)$ \\
\hline O4 & C31 & C33 & $121(4)$ \\
\hline
\end{tabular}

Table S6: Torsion Angles in ${ }^{\circ}$ for JJT521A.

\begin{tabular}{llllr}
\hline Atom & Atom & Atom & Atom & Angle/ $^{\circ}$ \\
\hline $\mathrm{Br} 1$ & $\mathrm{C} 23$ & $\mathrm{C} 24$ & $\mathrm{C} 25$ & $-176.3(4)$ \\
$\mathrm{B}$ 2 & $\mathrm{C} 15$ & $\mathrm{C} 16$ & $\mathrm{C} 17$ & $-179.9(4)$ \\
$\mathrm{N} 1$ & $\mathrm{C} 1$ & $\mathrm{C} 2$ & $\mathrm{O} 1$ & $177.9(4)$ \\
$\mathrm{N} 1$ & $\mathrm{C} 1$ & $\mathrm{C} 2$ & $\mathrm{~N} 2$ & $0.0(4)$ \\
$\mathrm{N} 1$ & $\mathrm{C} 1$ & $\mathrm{C} 4$ & $\mathrm{~N} 5$ & $-178.5(4)$ \\
$\mathrm{N} 1$ & $\mathrm{C} 1$ & $\mathrm{C} 5$ & $-4.3(7)$ \\
$\mathrm{N} 1$ & $\mathrm{C} 4$ & $\mathrm{C} 12$ & $64.3(6)$ \\
$\mathrm{N} 1$ & $\mathrm{C} 11$ & $\mathrm{C} 18$ & $-108.0(6)$ \\
$\mathrm{N} 1$ & $\mathrm{C} 11$ & $\mathrm{C} 20$ & $5.1(8)$ \\
$\mathrm{N} 1$ & $\mathrm{C} 1$ & $\mathrm{C} 26$ & $-176.0(5)$ \\
$\mathrm{N} 2$ & $\mathrm{C} 3$ & $\mathrm{C} 19$ & $-175.3(5)$
\end{tabular}




\begin{tabular}{|c|c|c|c|c|}
\hline Atom & Atom & Atom & Atom & Angle ${ }^{\circ}$ \\
\hline$\overline{\mathrm{N} 2}$ & C3 & C19 & $\mathrm{C} 26$ & $3.6(7)$ \\
\hline N4 & $\mathrm{C} 7$ & C8 & C9 & $-0.4(10)$ \\
\hline N5 & C4 & C5 & N3 & $-1.4(5)$ \\
\hline N5 & $\mathrm{C} 4$ & C5 & C10 & $-179.4(5)$ \\
\hline $\mathrm{C} 1$ & $\mathrm{~N} 1$ & $\mathrm{C} 3$ & N2 & $0.7(5)$ \\
\hline C1 & $\mathrm{N} 1$ & C3 & C19 & $-179.6(4)$ \\
\hline C1 & C4 & C5 & N3 & $-176.3(5)$ \\
\hline C1 & $\mathrm{C} 4$ & C5 & C10 & $5.7(9)$ \\
\hline C1 & C11 & $\mathrm{C} 12$ & $\mathrm{C} 13$ & $6.7(9)$ \\
\hline C1 & C11 & $\mathrm{C} 12$ & C17 & $-173.9(5)$ \\
\hline C1 & C11 & C18 & N6 & $173.9(5)$ \\
\hline $\mathrm{C} 2$ & N2 & $\mathrm{C} 3$ & $\mathrm{~N} 1$ & $-0.7(5)$ \\
\hline $\mathrm{C} 2$ & N2 & C3 & C19 & $179.6(4)$ \\
\hline $\mathrm{C} 2$ & $\mathrm{C} 1$ & $\mathrm{C} 4$ & N5 & $-66.0(5)$ \\
\hline $\mathrm{C} 2$ & $\mathrm{C} 1$ & $\mathrm{C} 4$ & C5 & $108.2(6)$ \\
\hline C2 & $\mathrm{C} 1$ & C11 & C12 & $-49.8(6)$ \\
\hline $\mathrm{C} 2$ & $\mathrm{C} 1$ & $\mathrm{C} 11$ & C18 & $137.9(5)$ \\
\hline C3 & $\mathrm{N} 1$ & C1 & C2 & $-0.4(4)$ \\
\hline C3 & $\mathrm{N} 1$ & C1 & C4 & $114.6(4)$ \\
\hline C3 & $\mathrm{N} 1$ & C1 & C11 & $-119.8(4)$ \\
\hline C3 & N2 & $\mathrm{C} 2$ & 01 & $-177.5(4)$ \\
\hline C3 & N2 & $\mathrm{C} 2$ & C1 & $0.4(5)$ \\
\hline C3 & C19 & $\mathrm{C} 20$ & C21 & $0.9(10)$ \\
\hline C3 & C19 & $\mathrm{C} 20$ & C25 & 179.8(5) \\
\hline C3 & C19 & $\mathrm{C} 26$ & N7 & $-179.5(5)$ \\
\hline $\mathrm{C} 4$ & N5 & $\mathrm{C} 6$ & N3 & $-0.8(5)$ \\
\hline $\mathrm{C} 4$ & N5 & $\mathrm{C} 6$ & $\mathrm{~N} 4$ & $179.3(4)$ \\
\hline C4 & N5 & C9 & C8 & $-179.5(5)$ \\
\hline C4 & $\mathrm{C} 1$ & $\mathrm{C} 2$ & 01 & $60.6(6)$ \\
\hline C4 & $\mathrm{C} 1$ & C2 & N2 & $-117.3(4)$ \\
\hline C4 & $\mathrm{C} 1$ & C11 & $\mathrm{C} 12$ & $-171.5(5)$ \\
\hline C4 & $\mathrm{C} 1$ & C11 & C18 & $16.1(7)$ \\
\hline C5 & N3 & C6 & $\mathrm{N} 4$ & $179.8(5)$ \\
\hline C5 & N3 & $\mathrm{C} 6$ & N5 & $0.0(6)$ \\
\hline C6 & N3 & C5 & C4 & $0.9(6)$ \\
\hline C6 & N3 & C5 & C10 & $179.2(5)$ \\
\hline C6 & N4 & C7 & C8 & $0.5(9)$ \\
\hline $\mathrm{C} 6$ & N5 & C4 & C1 & $176.9(4)$ \\
\hline C6 & N5 & C4 & C5 & $1.3(5)$ \\
\hline C6 & N5 & C9 & $\mathrm{C} 8$ & $1.6(7)$ \\
\hline $\mathrm{C} 7$ & N4 & C6 & N3 & $-179.4(5)$ \\
\hline C7 & N4 & C6 & N5 & $0.4(8)$ \\
\hline $\mathrm{C} 7$ & $\mathrm{C} 8$ & C9 & N5 & $-0.7(8)$ \\
\hline C9 & N5 & C4 & C1 & $-2.1(8)$ \\
\hline C9 & N5 & C4 & C5 & $-177.7(5)$ \\
\hline C9 & N5 & C6 & N3 & 178.3(4) \\
\hline C9 & N5 & $\mathrm{C} 6$ & $\mathrm{~N} 4$ & $-1.5(7)$ \\
\hline C11 & C1 & $\mathrm{C} 2$ & 01 & $-64.5(6)$ \\
\hline C11 & $\mathrm{C} 1$ & $\mathrm{C} 2$ & N2 & 117.6(4) \\
\hline C11 & C1 & C4 & N5 & $58.2(6)$ \\
\hline C11 & $\mathrm{C} 1$ & $\mathrm{C} 4$ & C5 & $-127.6(5)$ \\
\hline C11 & $\mathrm{C} 12$ & $\mathrm{C} 13$ & C14 & $-178.6(6)$ \\
\hline C11 & C12 & C17 & N6 & $0.0(6)$ \\
\hline C11 & C12 & C17 & C16 & 178.3(5) \\
\hline C12 & C11 & C18 & N6 & $0.4(6)$ \\
\hline C12 & $\mathrm{C} 13$ & C14 & C15 & $-0.9(9)$ \\
\hline C13 & C12 & C17 & N6 & 179.5(5) \\
\hline C13 & C12 & C17 & C16 & $-2.2(8)$ \\
\hline $\mathrm{C} 13$ & C14 & C15 & $\mathrm{Br} 2$ & $179.9(5)$ \\
\hline C13 & C14 & C15 & C16 & $-0.2(10)$ \\
\hline
\end{tabular}




\begin{tabular}{llllr}
\hline Atom & Atom & Atom & Atom & Angle $^{\circ}$ \\
\hline $\mathrm{C} 14$ & $\mathrm{C} 15$ & $\mathrm{C} 16$ & $\mathrm{C} 17$ & $0.1(9)$ \\
$\mathrm{C} 15$ & $\mathrm{C} 16$ & $\mathrm{C} 17$ & $\mathrm{~N} 6$ & $179.0(6)$ \\
$\mathrm{C} 15$ & $\mathrm{C} 16$ & $\mathrm{C} 17$ & $\mathrm{C} 12$ & $1.1(8)$ \\
$\mathrm{C} 17$ & $\mathrm{C} 18$ & $\mathrm{C} 11$ & $-0.4(7)$ \\
$\mathrm{C} 17$ & $\mathrm{C} 6$ & $\mathrm{C} 14$ & $2.0(8)$ \\
$\mathrm{C} 18$ & $\mathrm{C} 13$ & $\mathrm{C} 12$ & $0.3(6)$ \\
$\mathrm{C} 18$ & $\mathrm{C} 17$ & $\mathrm{C} 16$ & $-177.9(6)$ \\
$\mathrm{C} 18$ & $\mathrm{~N} 6$ & $\mathrm{C} 17$ & $\mathrm{C} 13$ & $-179.6(6)$ \\
$\mathrm{C} 18$ & $\mathrm{C} 12$ & $\mathrm{C} 17$ & $-0.2(6)$ \\
$\mathrm{C} 19$ & $\mathrm{C} 12$ & $\mathrm{C} 22$ & $-179.4(6)$ \\
$\mathrm{C} 19$ & $\mathrm{C} 21$ & $\mathrm{~N} 7$ & $-0.9(6)$ \\
$\mathrm{C} 19$ & $\mathrm{C} 25$ & $\mathrm{C} 24$ & $178.1(5)$ \\
$\mathrm{C} 20$ & $\mathrm{C} 11$ & $\mathrm{~N} 7$ & $-0.4(6)$ \\
$\mathrm{C} 20$ & $\mathrm{C} 11$ & $\mathrm{C} 23$ & $1.3(9)$ \\
$\mathrm{C} 21$ & $\mathrm{C} 20$ & $\mathrm{C} 26$ & $\mathrm{~N} 7$ & $178.3(5)$ \\
$\mathrm{C} 21$ & $\mathrm{C} 20$ & $\mathrm{C} 24$ & $-2.7(8)$ \\
$\mathrm{C} 21$ & $\mathrm{C} 22$ & $\mathrm{~B} 1$ & $175.4(5)$ \\
$\mathrm{C} 21$ & $\mathrm{C} 25$ & $\mathrm{C} 24$ & $-3.8(10)$ \\
$\mathrm{C} 22$ & $\mathrm{C} 19$ & $\mathrm{C} 25$ & $2.8(10)$ \\
$\mathrm{C} 23$ & $\mathrm{C} 21$ & $\mathrm{C} 25$ & $\mathrm{~N} 7$ & $179.2(6)$ \\
$\mathrm{C} 23$ & $\mathrm{C} 20$ & $\mathrm{C} 20$ & $0.5(9)$ \\
$\mathrm{C} 25$ & $\mathrm{C} 23$ & $\mathrm{C} 19$ & $-0.2(7)$ \\
$\mathrm{C} 25$ & $\mathrm{C} 20$ & $\mathrm{C} 22$ & $1.8(8)$ \\
$\mathrm{C} 26$ & $\mathrm{C} 23$ & $\mathrm{C} 20$ & $0.7(6)$ \\
$\mathrm{C} 26$ & $\mathrm{C} 24$ & $\mathrm{C} 24$ & $-178.3(6)$ \\
$\mathrm{C} 26$ & $\mathrm{C} 21$ & $-178.2(6)$ \\
$\mathrm{C} 26$ & $\mathrm{C} 25$ & $\mathrm{C} 25$ & $0.8(6)$
\end{tabular}

Table S7: Hydrogen Fractional Atomic Coordinates $\left(\times 10^{4}\right)$ and Equivalent Isotropic Displacement Parameters $\left(\AA^{2} \times 10^{3}\right)$ for JJT521A. $U_{\text {eq }}$ is defined as $1 / 3$ of the trace of the orthogonalised $U_{i j}$.

\begin{tabular}{|c|c|c|c|c|}
\hline Atom & $\mathbf{x}$ & $y$ & $z$ & $U_{\text {eq }}$ \\
\hline$\overline{\mathrm{H} 2}$ & 4869.36 & 1118.76 & 4863.67 & 57 \\
\hline $\mathrm{H} 6$ & 9366.37 & 778.56 & 970.99 & 71 \\
\hline $\mathrm{H} 7$ & 3235.98 & 4476.43 & 5968.47 & 76 \\
\hline $\mathrm{H} 7 \mathrm{~A}$ & 5028.11 & -2748.16 & 607.18 & 86 \\
\hline $\mathrm{H} 8$ & 6679.83 & -2799.81 & 1677.78 & 81 \\
\hline $\mathrm{H} 9$ & 6736.44 & -1203.28 & 2365.6 & 67 \\
\hline $\mathrm{H} 10 \mathrm{~A}$ & 2398.56 & 2802.26 & 922.23 & 109 \\
\hline $\mathrm{H} 10 \mathrm{~B}$ & 3588.8 & 3116.96 & 1351.86 & 109 \\
\hline $\mathrm{H} 10 \mathrm{C}$ & 2586.14 & 2684.28 & 2059.29 & 109 \\
\hline $\mathrm{H} 13$ & 7564.69 & 1317.91 & 4363.63 & 68 \\
\hline $\mathrm{H} 14$ & 9498.48 & 1470.57 & 4925.63 & 76 \\
\hline $\mathrm{H} 16$ & 11105.25 & 1049.18 & 2308.77 & 70 \\
\hline $\mathrm{H} 18$ & 7142.35 & 784.63 & 927.51 & 68 \\
\hline $\mathrm{H} 21$ & 4264.19 & 4756.56 & 2331.72 & 73 \\
\hline $\mathrm{H} 22$ & 3534.38 & 6694.64 & 2125.23 & 82 \\
\hline $\mathrm{H} 24$ & 2710.62 & 6651.82 & 4986.58 & 75 \\
\hline $\mathrm{H} 26$ & 4130.44 & 2600.01 & 5639.47 & 69 \\
\hline $\mathrm{H} 2 \mathrm{~A}$ & $8440(100)$ & $9000(90)$ & $-280(70)$ & 115 \\
\hline $\mathrm{H} 27 \mathrm{~A}$ & 9449.06 & 7365.94 & 327.63 & 146 \\
\hline $\mathrm{H} 27 \mathrm{~B}$ & 8744.32 & 8068.54 & 1126.35 & 146 \\
\hline $\mathrm{H} 28 \mathrm{~A}$ & 10549.34 & 8517.45 & 1530.1 & 210 \\
\hline $\mathrm{H} 28 \mathrm{~B}$ & 11271.58 & 7986.16 & 648.19 & 210 \\
\hline $\mathrm{H} 28 \mathrm{C}$ & 10849.87 & 7196.31 & 1532.44 & 210 \\
\hline
\end{tabular}




\begin{tabular}{lrrrr}
\hline Atom & $\mathbf{x}$ & $\mathbf{y}$ & $\mathbf{z}$ & $\boldsymbol{U}_{\text {eq }}$ \\
\hline H3 & 6157.53 & 3515.94 & 1958.35 & 192 \\
H29A & 6218.68 & 3607.33 & 492.39 & 192 \\
H29B & 7621.07 & 3079.58 & 859.45 & 192 \\
H30A & 7921.08 & 4929.4 & 566.54 & 337 \\
H30B & 6633.39 & 5222.47 & -28.74 & 337 \\
H30C & 7803.14 & 4321.74 & -343.57 & 337 \\
H4 & 7344.86 & 4783.88 & 2519.75 & 170 \\
H31A & 9378.91 & 4519.98 & 2292.49 & 223 \\
H31B & 9084.08 & 3787.42 & 3260.81 & 223 \\
H31C & 9099.67 & 3809.16 & 2759.66 & 223 \\
H31D & 9244.43 & 4453.71 & 3632.41 & 223 \\
H32A & 10008.05 & 4611.16 & 4099.08 & 418 \\
H32B & 10541.55 & 5168.16 & 3131.18 & 418 \\
H32C & 9304.56 & 5826.46 & 3600.88 & 418 \\
H33A & 10817.07 & 4655.47 & 2656.9 & 418 \\
H33B & 9873.77 & 4904.07 & 1760.3 & 418 \\
H33C & 9867.87 & 5846.97 & 2423.7 & 418
\end{tabular}

Table S8: Hydrogen Bond information for JJT521A.

\begin{tabular}{lllcrrr}
\hline $\mathbf{D}$ & $\mathbf{H}$ & $\mathbf{A}$ & $\mathbf{d}(\mathbf{D}-\mathbf{H}) / \mathbf{A}$ & $\mathbf{d}(\mathbf{H}-\mathbf{A}) / \mathbf{A}$ & $\mathbf{d}(\mathbf{D}-\mathbf{A}) / \mathbf{A}$ & \multicolumn{1}{c}{$\mathbf{D}-\mathbf{H}-\mathbf{A} / \mathbf{d e g}$} \\
\hline $\mathrm{N} 2$ & $\mathrm{H} 2$ & $\mathrm{O} 1^{1}$ & 0.86 & 1.95 & $2.794(5)$ & 165.1 \\
$\mathrm{~N} 6$ & $\mathrm{H} 6$ & $\mathrm{O}{ }^{2}$ & 0.86 & 2.09 & $2.900(6)$ & 157.2 \\
$\mathrm{~N} 7$ & $\mathrm{H} 7$ & 0.86 & 1.97 & $2.819(7)$ & 168.0 \\
$\mathrm{C} 9$ & $\mathrm{O}$ & 0.93 & 2.47 & $2.923(6)$ & 110.2 \\
$\mathrm{O} 2$ & $\mathrm{H} 9$ & $\mathrm{O} 1$ & $0.81(11)$ & $2.03(11)$ & $2.837(6)$ & $172(10)$ \\
$\mathrm{O} 3$ & $\mathrm{H} 2 \mathrm{~A}$ & $\mathrm{~N} 3^{4}$ & 0.82 & 2.11 & $2.921(7)$ & 168.2 \\
$\mathrm{O} 4$ & $\mathrm{H} 3$ & $\mathrm{~N} 1$ & 0.82 & 1.89 & $2.711(11)$ & 176.0
\end{tabular}

$\overline{11-x,-y, 1-z ;}{ }^{2} 2-x, 1-y,-z ;{ }^{31} 1-x, 1-y, 1-z ;{ }^{4} 1-x, 1-y,-z$

Table S9: Atomic Occupancies for all atoms that are not fully occupied in JJT521A.

\begin{tabular}{lr}
\hline Atom & \multicolumn{1}{c}{ Occupancy } \\
\hline H31A & $0.76(3)$ \\
H31B & $0.76(3)$ \\
H31C & $0.24(3)$ \\
H31D & $0.24(3)$ \\
C32 & $0.76(3)$ \\
H32A & $0.76(3)$ \\
H32B & $0.76(3)$ \\
H32C & $0.76(3)$ \\
C33 & $0.24(3)$ \\
H33A & $0.24(3)$ \\
H33B & $0.24(3)$ \\
H33C & $0.24(3)$
\end{tabular}


Solvent molecules were found to reside in the lattice void, which is presumably octane resulting from crystallization. Attempts to model these solvents and or redefine as $\mathrm{CH}_{2} \mathrm{Cl}_{2}$ failed to generate a chemically sensible model. The SQUEEZE (P.v.d. Sluis \& Spek, 1990) function of PLATON ( Spex, 2003) was used to eliminate the contribution of the electron density in the void from the intensity data. The total solvent area volume was found to be $1377 \tilde{A}$...3, with electron count of about 237 electrons. This corresponds to approximately three molecules of octane residing in the cell. Although the electron count is slightly higher than calculated, the large volume suggests that this void is mostly consumed by octane and not the other potential solvent, dichloromethane. The calculate $F(000)$ and density was calculated for the cell containing three molecules of octane per cell or 1.5 per molecule of interest. The refinement was carried out on the new reflection file generated by PLATON.

CrysAlisPro (Rigaku, V1.171.41.108a, 2021)

O.V. Dolomanov and L.J. Bourhis and R.J. Gildea and J.A.K. Howard and H. Puschmann, Olex2: A complete structure solution, refinement and analysis program, J. Appl. Cryst., (2009), 42, 339-341.

Sheldrick, G.M., Crystal structure refinement with ShelXL, Acta Cryst., (2015), C71, 3-8.

Sheldrick, G.M., ShelXT-Integrated space-group and crystal-structure determination, Acta Cryst., (2015), A71, 3-8.

The Rigaku Synergy S Diffractometer was purchased with Support from the MRI program by the National Science Foundation under Grant No. 1919565. 
NMR Spectra

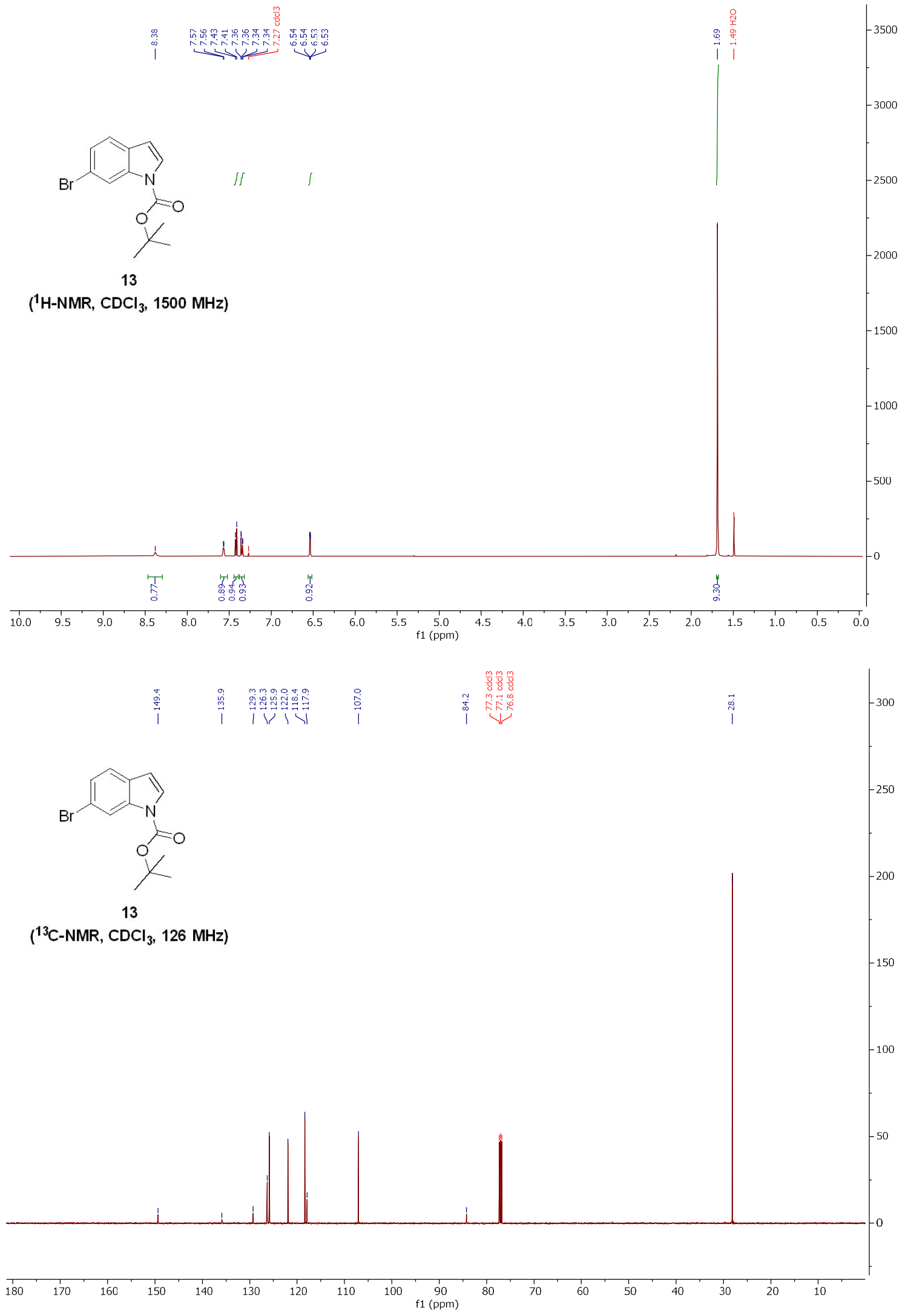




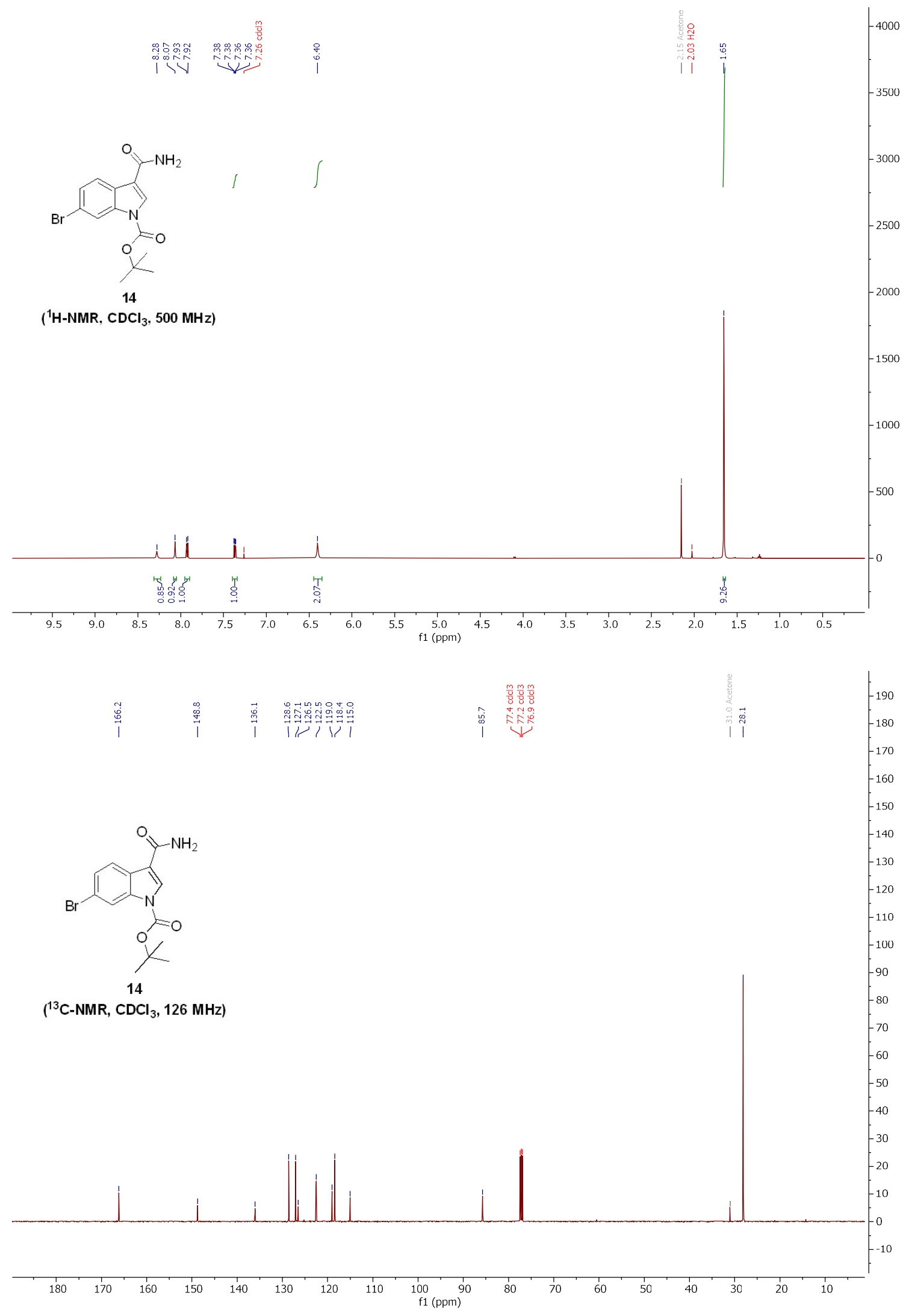




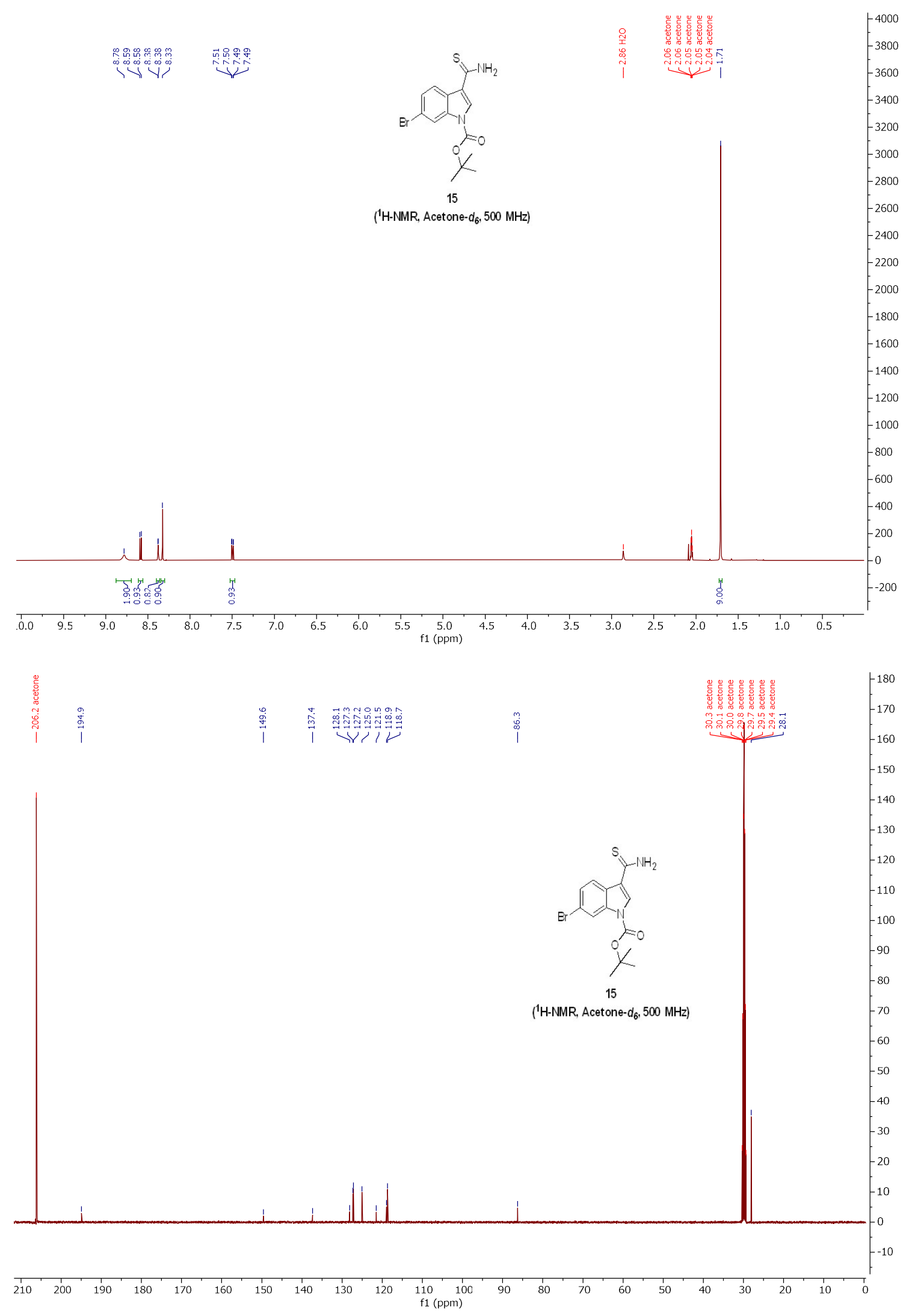




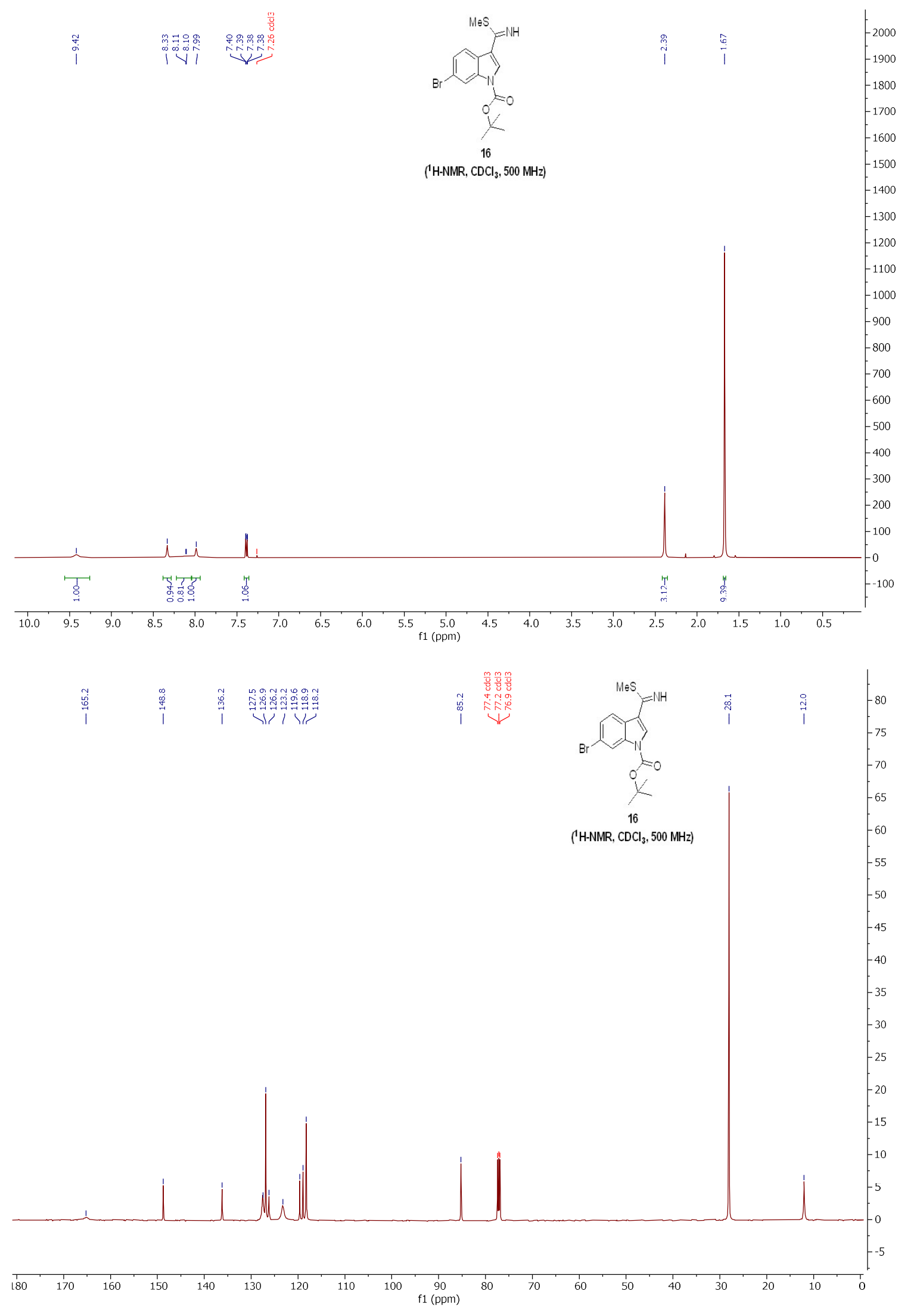




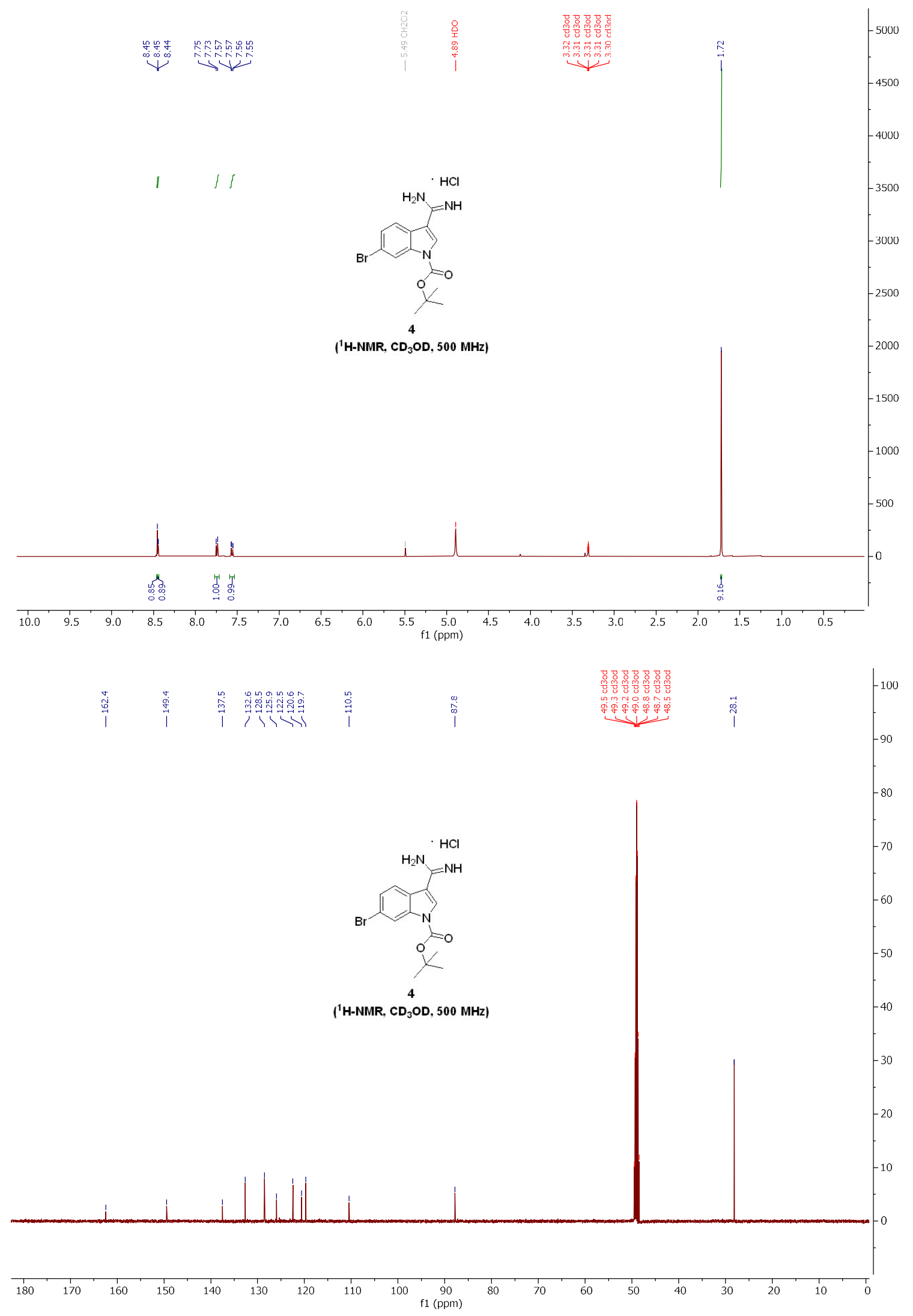




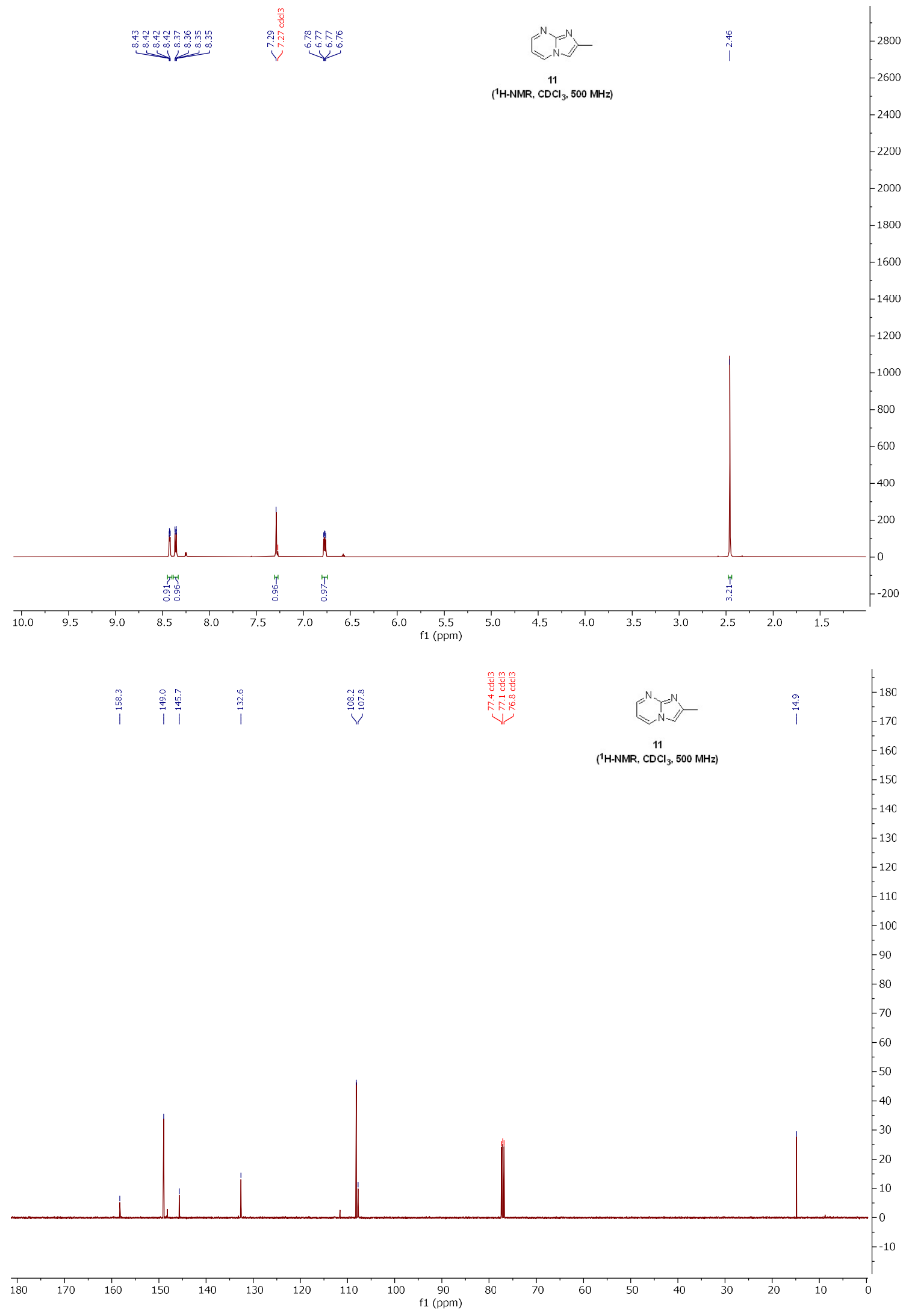




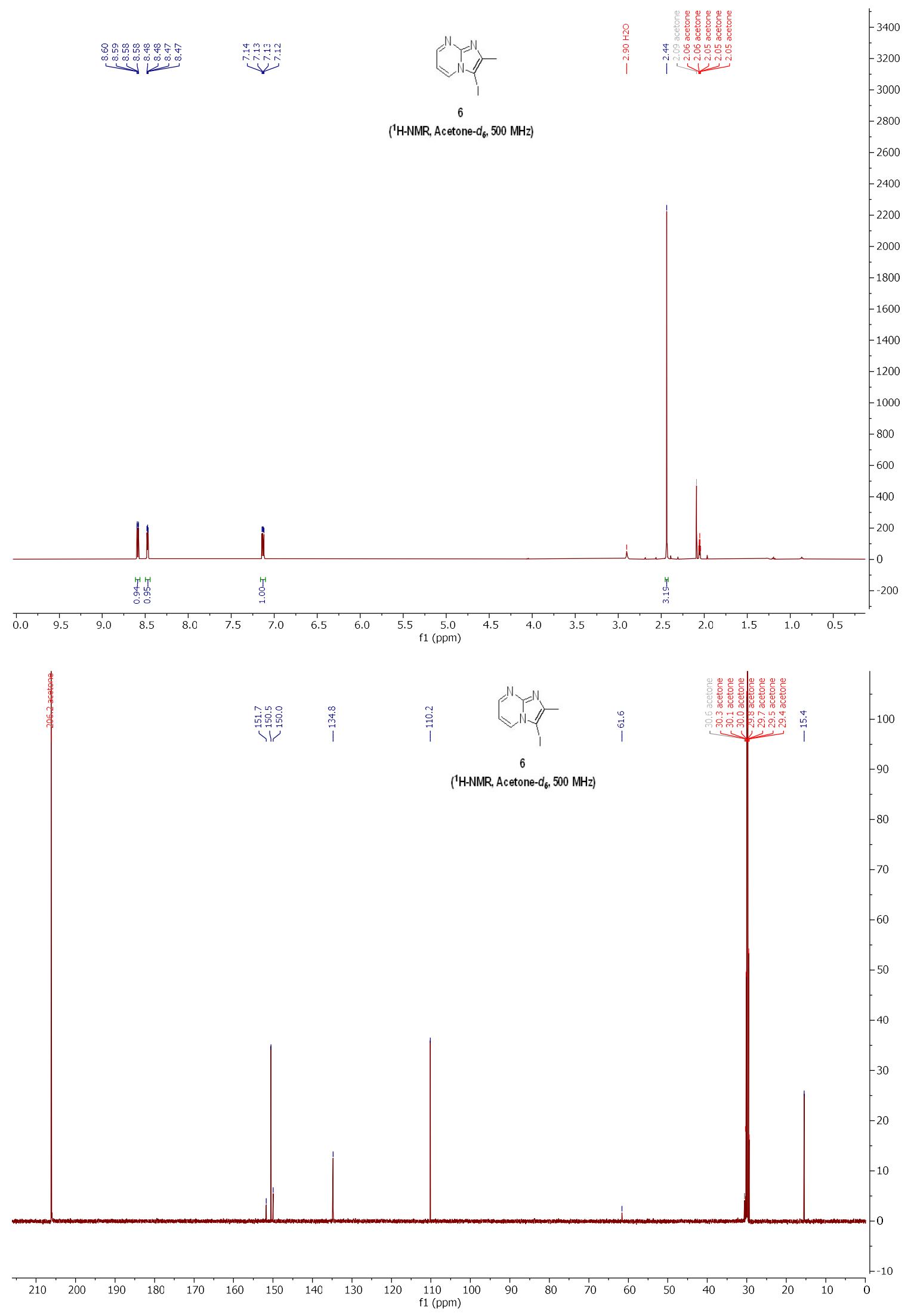




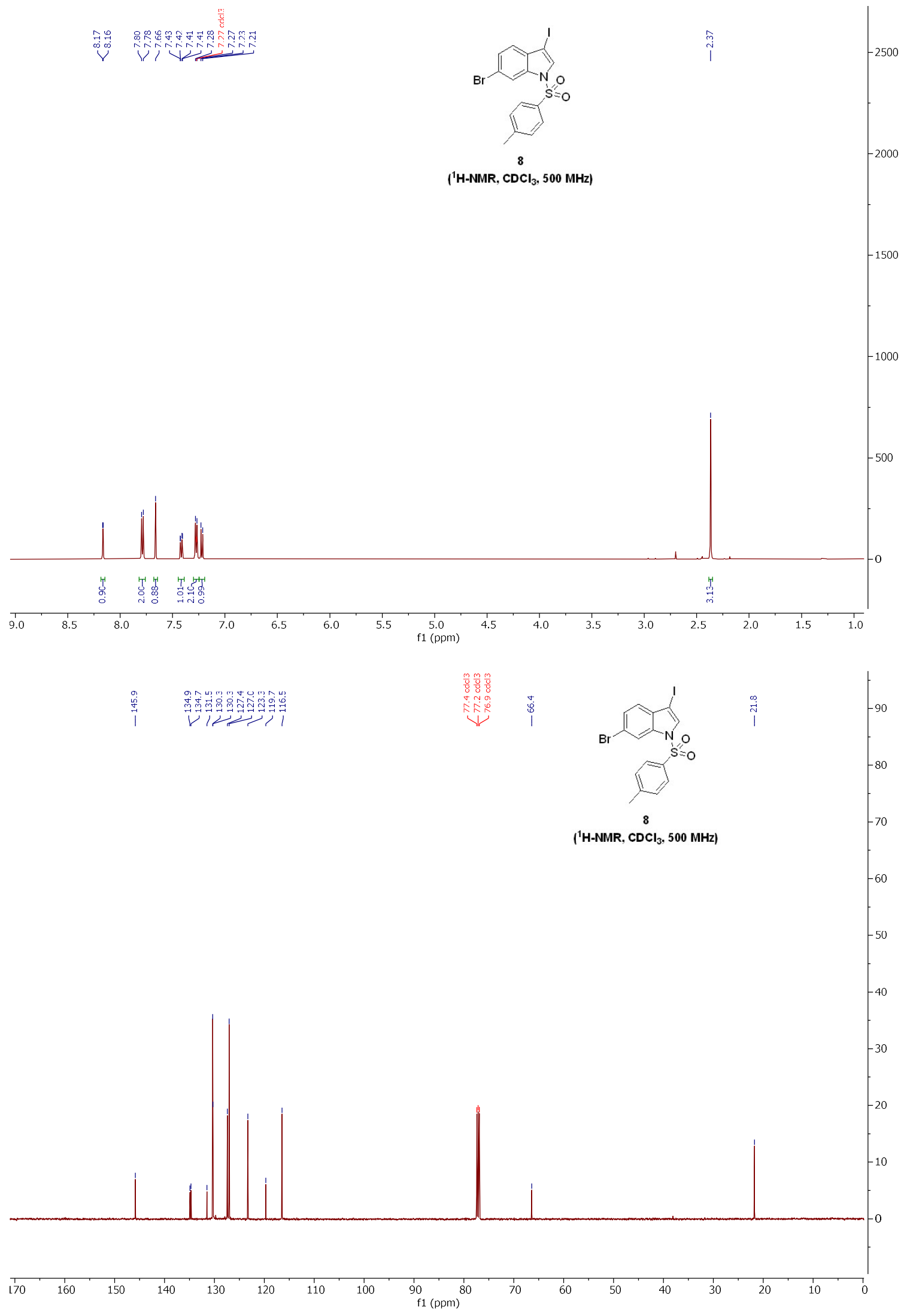




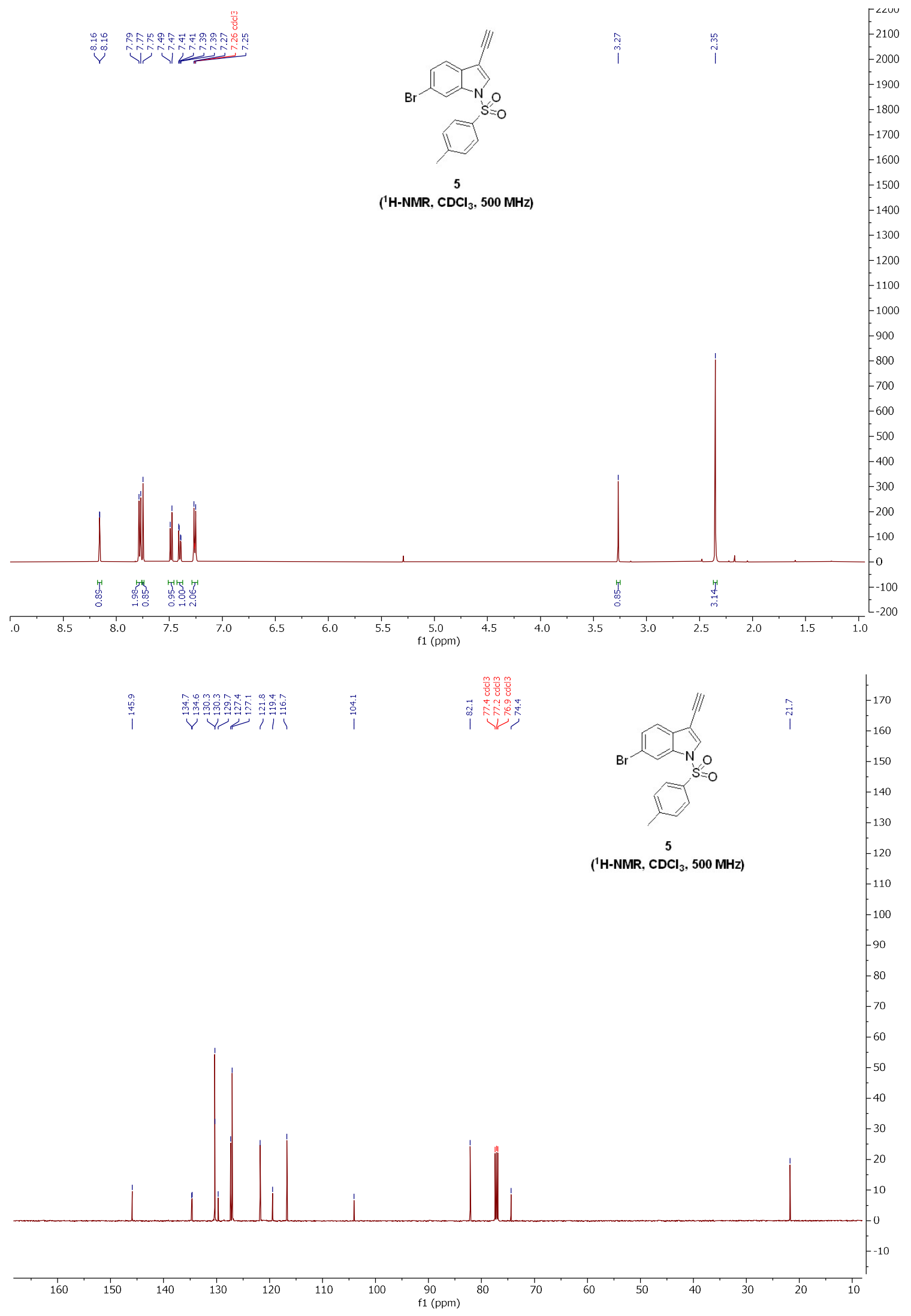


$\frac{m}{\tau}$

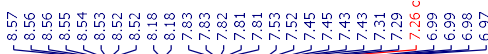
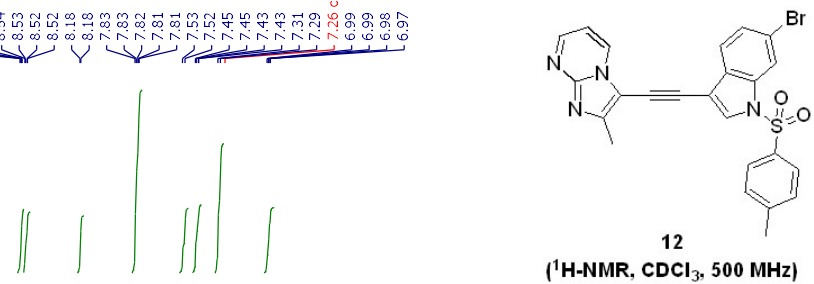

( ${ }^{1} \mathrm{H}-\mathrm{NMR}, \mathrm{CDCl}_{3}, 500 \mathrm{MHz}$ )

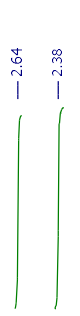

$-3000$

2500

2000

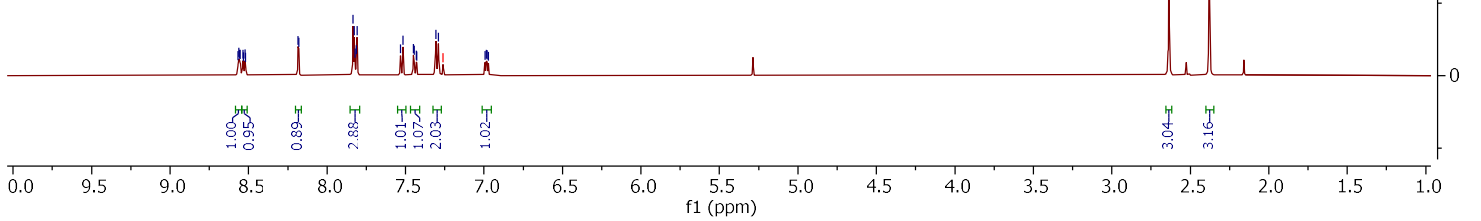

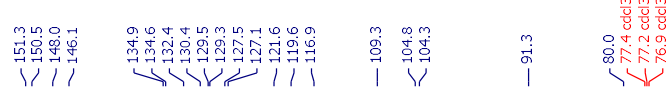
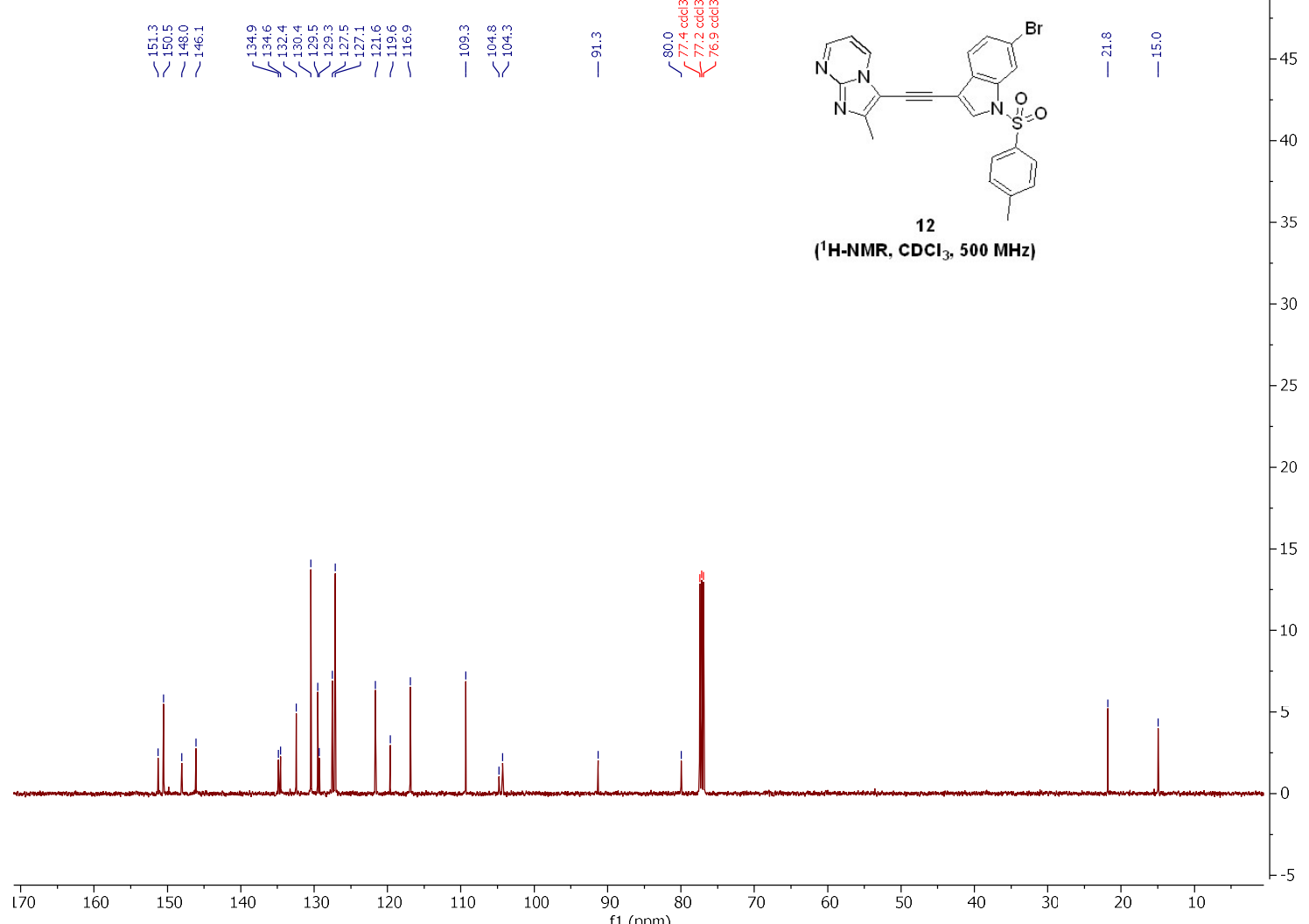


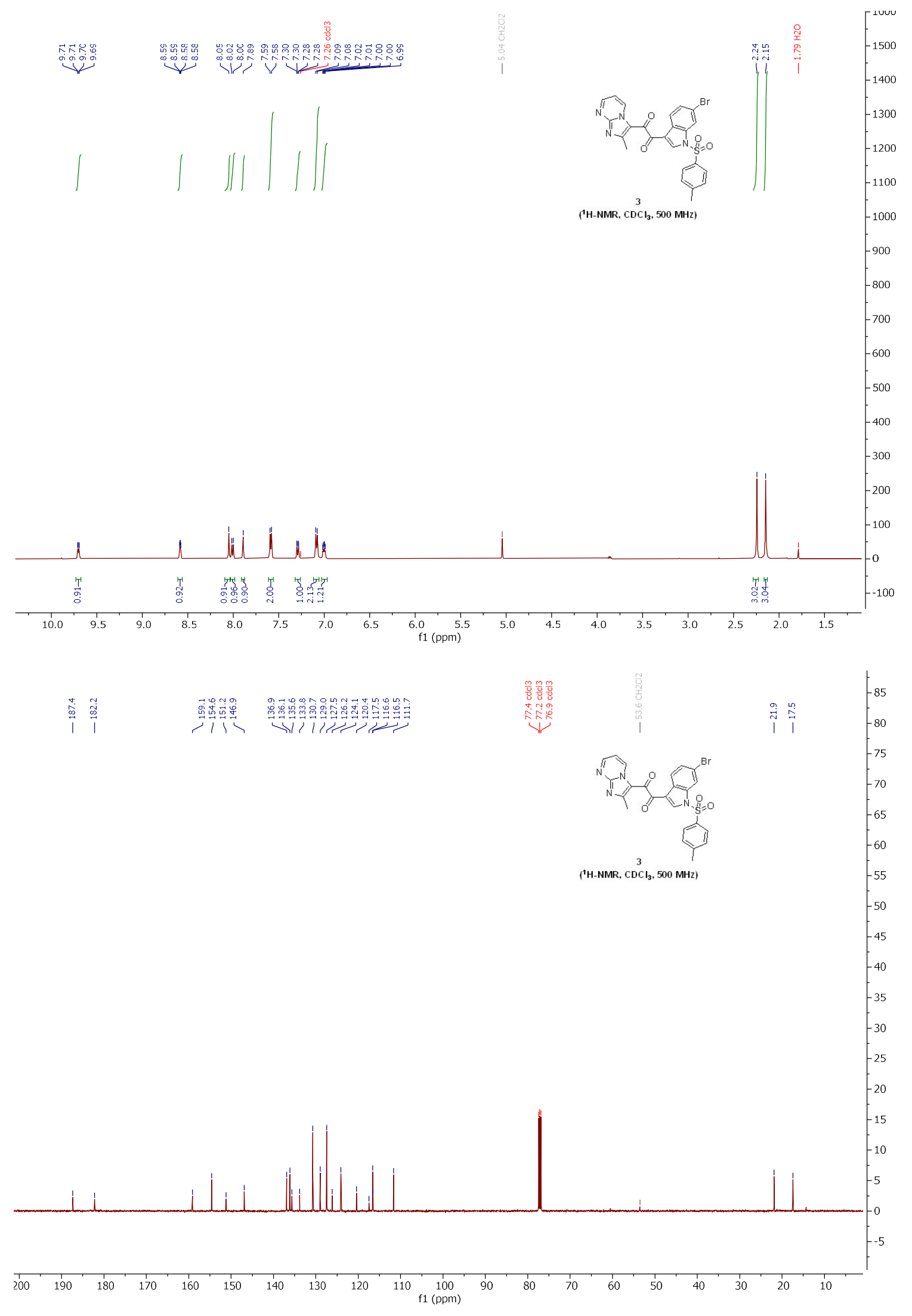




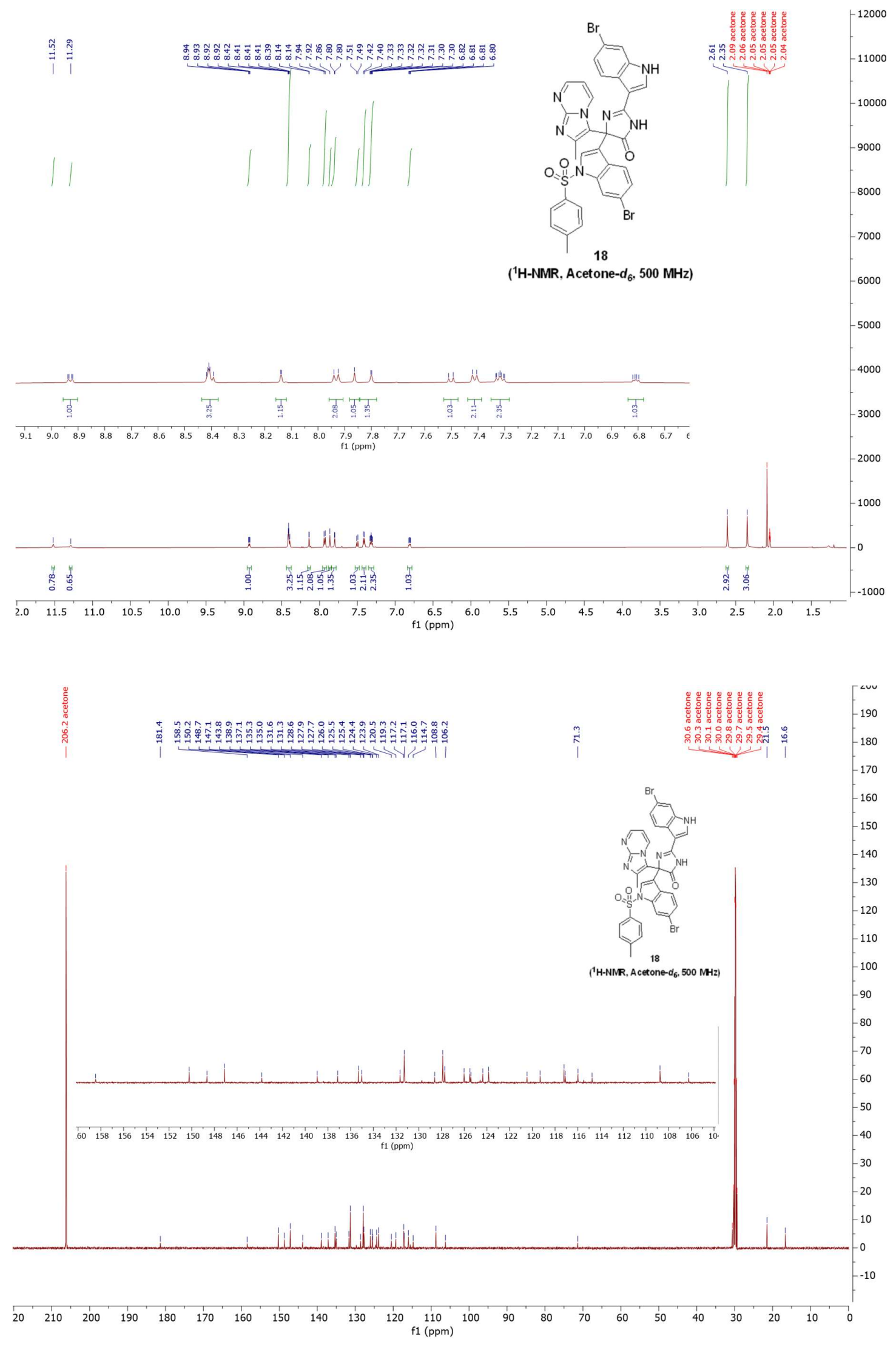



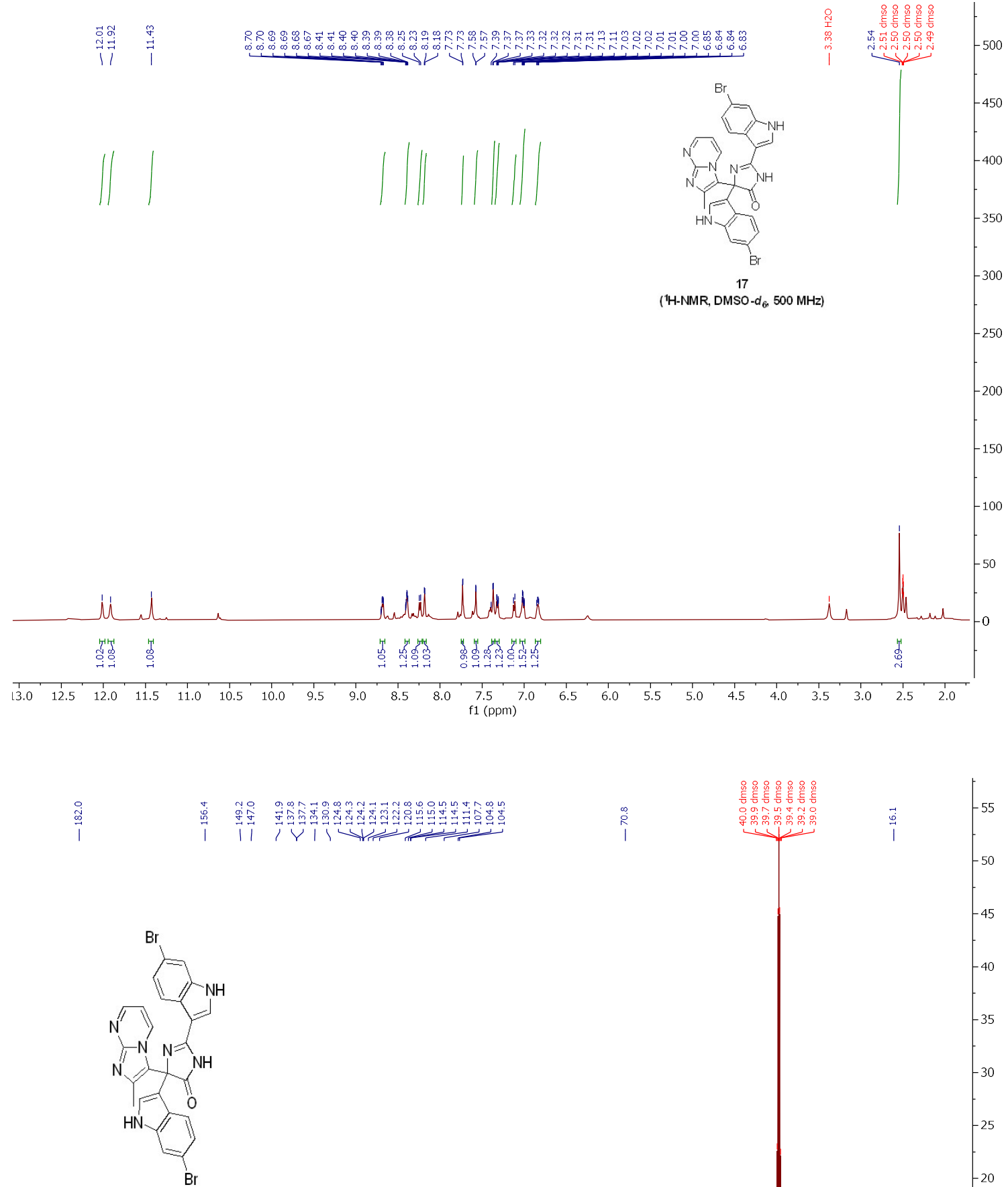

17

$\left({ }^{13} \mathrm{C}-\mathrm{NMR}\right.$, DMSO-d $\left.\mathrm{d}_{6}, 126 \mathrm{MHz}\right)$

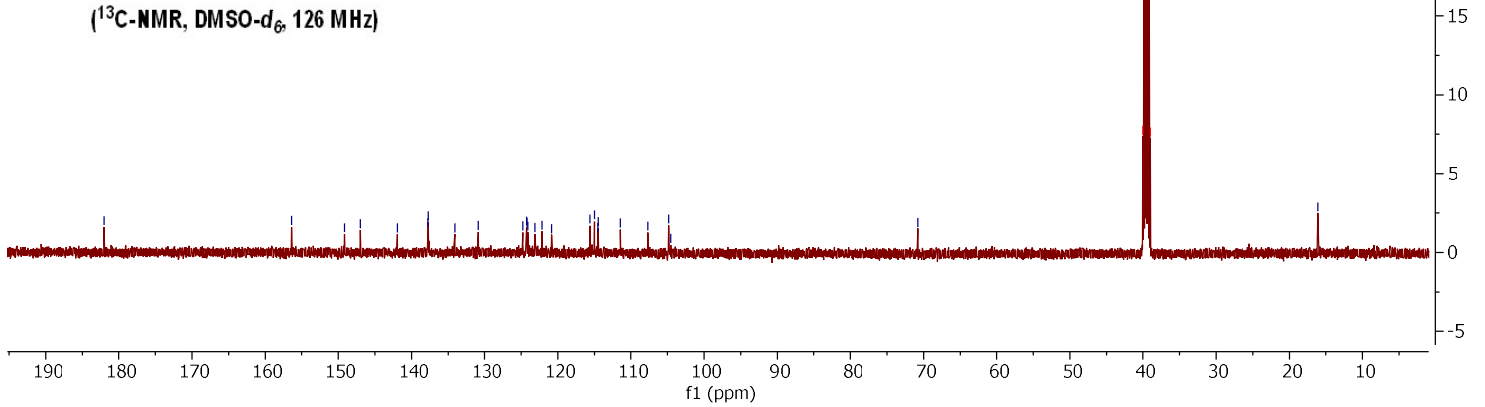




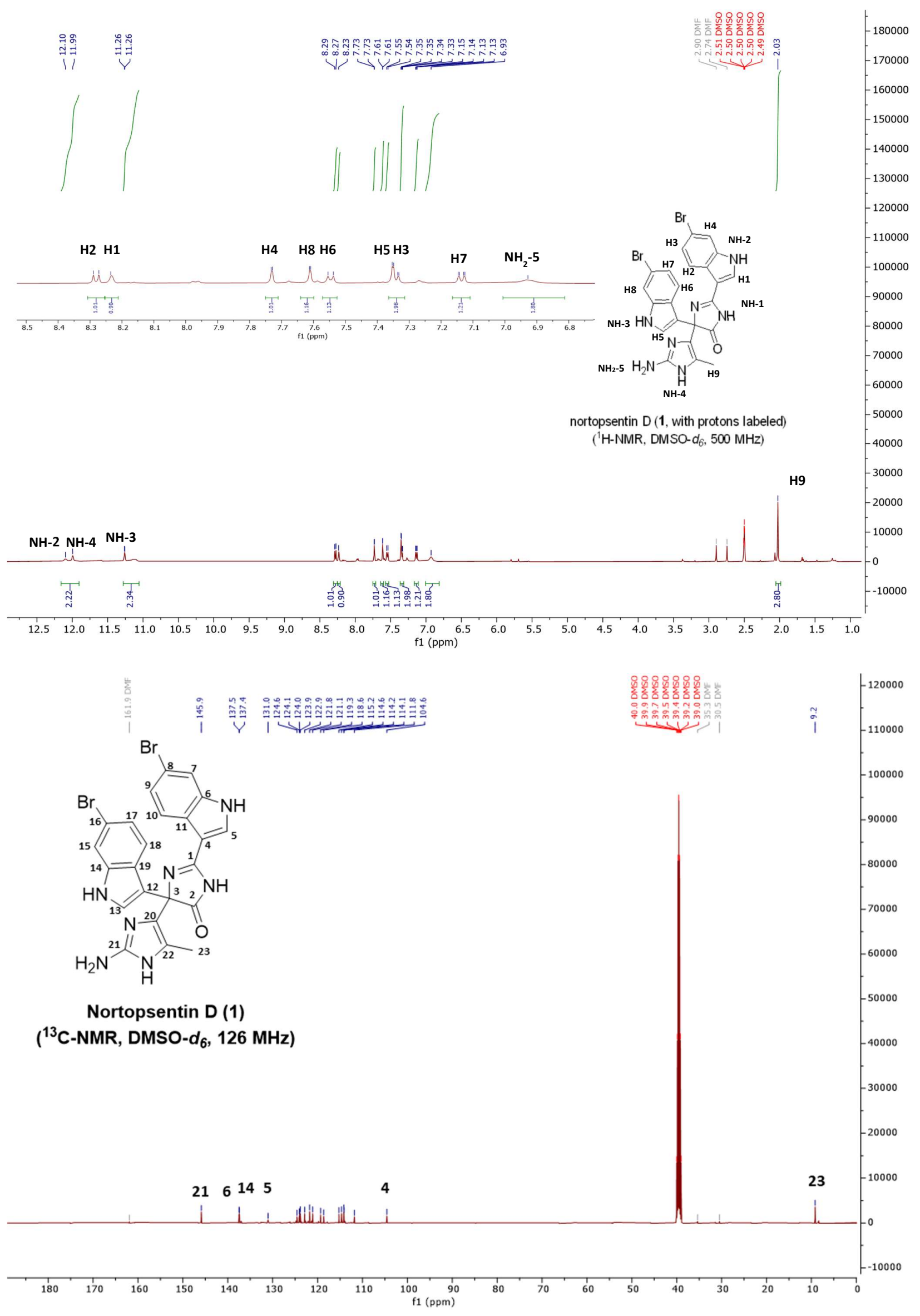




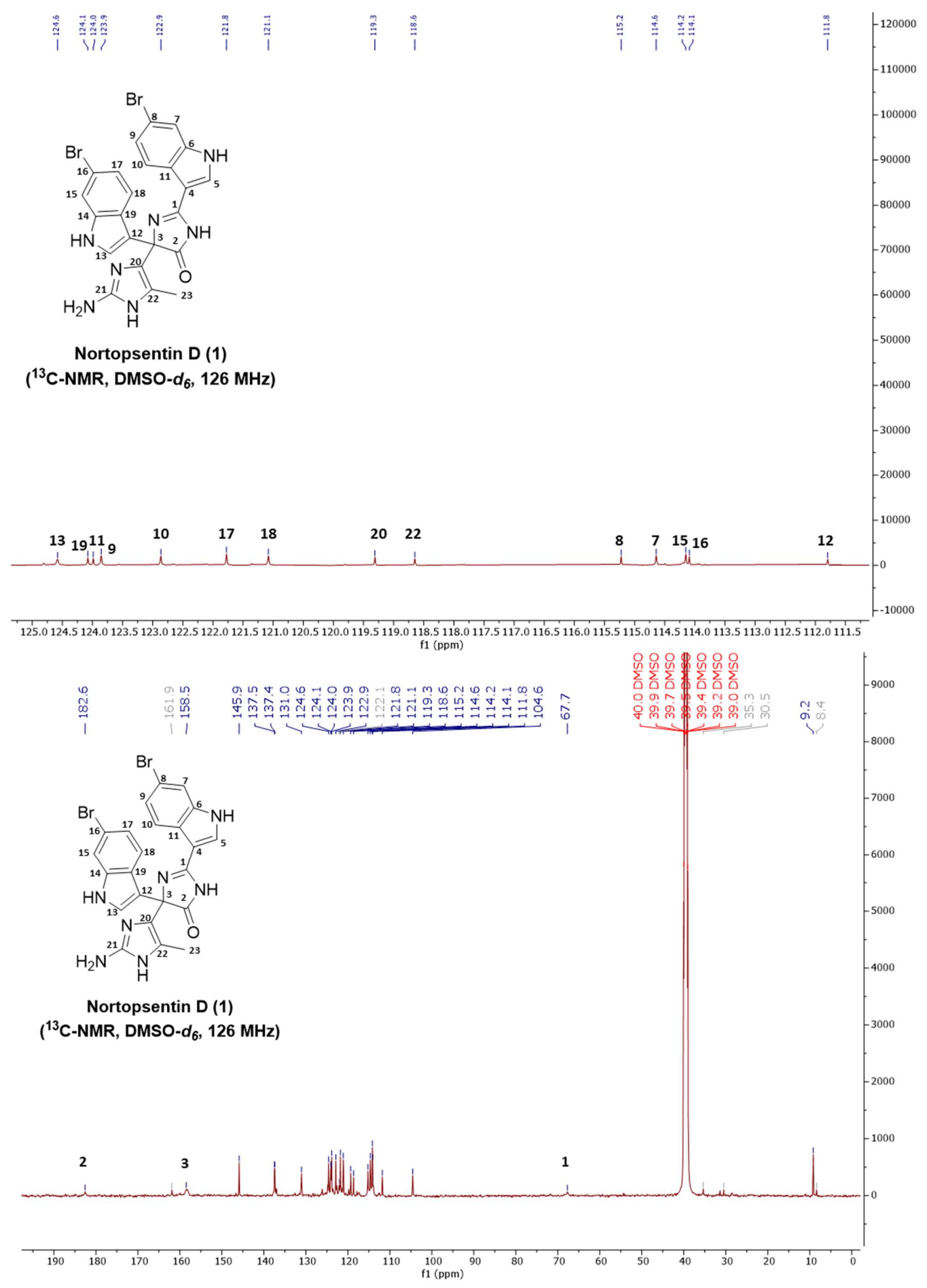

Apodization enhanced to exponential $=8 \mathrm{~Hz}$ 